\title{
Sustained TNF signaling is required for the synaptic and behavioral response to acute stress
}

Gina M Kemp, Haider F Altimimi, Yoonmi Nho, Renu Heir, David Stellwagen\#

Department of Neurology and Neurosurgery, Centre for Research in Neuroscience, Research Institute of the McGill University Health Center, Montréal, Québec, Canada.

\# Corresponding author:

Centre for Research in Neuroscience, Montreal General Hospital, 1650 Cedar Ave. L7-132, Montréal, QC H3G 1A4, Canada. Tel.: 514-934-8094, Fax: 514-934-8216; E-mail: david.stellwagen@mcgill.ca

\section{Running Title}

TNF mediates stress-induced plasticity

\section{Keywords}

Stress, inflammation, corticosterone, TNF, AMPA, hippocampus, anxiety

Author contributions: G.M.K, H.F.A., and D.S. designed the research; G.M.K, H.F.A., Y.N., and R.H. performed experiments; G.M.K, H.F.A., Y.N., and R.H. analyzed data; G.M.K, H.F.A., and D.S. wrote the manuscript.

The authors declare no conflict of interest.

Acknowledgements: This work was supported by the Canadian Institutes for Health Research and Natural Sciences and Engineering Research Council of Canada. G.M.K was supported by a fellowship from the Canada First Research Excellence Fund, awarded to McGill University for the Healthy Brains for Healthy Lives initiative. H.F.A. was supported by doctoral awards from the Heart and Stroke Foundation of Canada, and the Research Institute of the McGill University Health Centre. We kindly thank Xencor for the donation of XPro1595. Schematic figures were created using BioRender. 


\begin{abstract}
Acute stress triggers plasticity of forebrain synapses as well as behavioral changes. Here we reveal that Tumor Necrosis Factor $\alpha$ (TNF) is a required downstream mediator of the stress response in mice, necessary for stress-induced synaptic potentiation in the ventral hippocampus and for an increase in anxiety-like behaviour. Acute stress is sufficient to activate microglia, triggering the long-term release TNF. Critically, on-going TNF signaling in the ventral hippocampus is necessary to sustain both the stressinduced synaptic and behavioral changes, as these could be reversed hours after induction by antagonizing TNF signaling. This demonstrates that TNF maintains the synaptic and behavioral stress response in vivo, making TNF a potential novel therapeutic target for stress disorders.
\end{abstract}

\title{
Introduction
}

Stress drives adaptive responses critical for an organism's physiological homeostasis and function. However, unregulated activation of the stress response results in significant problems; stress is a major contributing factor to the development of a number of psychiatric diseases including posttraumatic stress disorder and other anxiety disorders (Brewin, 2005; McEwen et al., 2015). There are long-standing observations of reciprocal interactions between stress and the immune system; stimulation of the immune system is a potent activator of the hypothalamic-pituitary-adrenal (HPA) axis, and the output of the HPA axis (corticosteroid (Cort)) can exacerbate inflammation in the brain under certain conditions or be an immune suppressant in other conditions (Costa-Pinto and Palermo-Neto, 2010; Dhabhar, 2009; Sorrells et al., 2009). Further, elevated pro-inflammatory cytokine levels are observed in patients with generalized anxiety disorder (Hou et al., 2017; Tang et al., 2018) and even acute stressors can increase cytokines levels in humans (Muscatell et al., 2015; Slavish et al., 2015).

The role of cytokines in the stress response and development of anxiety is not clear. Immune signaling molecules appear to be involved in stress conditions, including chronic mild stress (You et al., 2011); repeated social defeat (Wohleb et al., 2011); stress-induced ischemia (Caso et al., 2006); and HPA regulation (Turnbull and Rivier, 1999). Acute stress alone can induce peripheral cytokine production (Qing et al., 2020; Serrats et al., 2017), and cytokines are linked to the stress-induced development of anhedonia (Koo and Duman, 2008) and anxiety (Iwata et al., 2016). Tumor Necrosis Factor $\alpha$ (TNF) in particular may play a causal role in the development of anxiety-like behaviors, as blocking TNF signaling 
reduced the expression of anxiety-like behaviors induced by peripheral inflammation (Camara et al., 2015), chronic pain (Chen et al., 2013), obesity (Fourrier et al., 2019), or experimental autoimmune encephalomyelitis (Haji et al., 2012). Moreover, elevating central TNF levels by direct intracerebroventricular injection increases anxiety-like behaviors in mice (Haji et al., 2012). This suggests that it is possible that stress-induced anxiety is mediated by TNF.

A single bout of stress is reported to vary in its ability to stimulate TNF expression but generally observed to trigger an elevation (Iwata et al., 2016; Madrigal et al., 2002; Nguyen et al., 1998; O'Connor et al., 2003; Ohgidani et al., 2016; Vecchiarelli et al., 2016), similar to what is seen for chronic stress (Goshen et al., 2008; You et al., 2011). In particular, a combination of restraint and water immersion will increase TNF levels in the hippocampus due to microglia activation (Ohgidani et al., 2016). The elevation of TNF in the hippocampus is intriguing as there is strong evidence to implicate the ventral hippocampus in the regulation of anxiety-like behaviour. Unlike the dorsal hippocampus, a key structure for spatial memory, the ventral hippocampus modulates emotional states (Fanselow and Dong, 2010; Strange et al., 2014). This is particularly true for anxiety, as lesioning the ventral hippocampus is anxiolytic (Bannerman et al., 2002; Kjelstrup et al., 2002). Anxiety-responsive cells are found in the ventral hippocampus, and optogenetic activation of the terminals of these cells in the lateral hypothalamic area increased avoidance and anxiety-like behaviour (Jimenez et al., 2018). Critically, a variety of optogenetic and pharmacologic manipulation of the ventral hippocampus (and its inputs and outputs) directly alter anxiety-like behaviours (Felix-Ortiz et al., 2013; Jimenez et al., 2018; Kheirbek et al., 2013; Kjaerby et al., 2016; Padilla-Coreano et al., 2016; Parfitt et al., 2017; Wu and Hen, 2014). The ventral hippocampus has also been shown to be involved in descending regulation of the HPA in response to acute stress (Radley and Sawchenko, 2011).

However, whether the increase in hippocampal TNF is instructive to stress-related synaptic modulation and associated anxiety-like behaviors remains unexplored. In light of this, we investigated the mechanistic role for TNF, an inflammatory signaling molecule shown to play a role in the homeostasis of synaptic transmission (Stellwagen and Malenka, 2006), in the stress response. Here we demonstrate that acute stress induces TNF production within the ventral hippocampus. Further, sustained hippocampal TNF signaling is required to maintain the synaptic potentiation and the increase in anxietylike behavior induced by stress. 


\section{Results}

We used an acute stressor to study the role of TNF on subsequent stress induced synaptic and behavioral changes (Fig $1 \mathrm{~A}$ ). Exposure of adult male mice to 20 min of forced swimming (at $23-25^{\circ} \mathrm{C}$ ) was sufficient to increase anxiety-like behaviour $24 \mathrm{~h}$ later as measured by both the light-dark box and open field test (Fig 1B). This effect was not stressor dependent, as $1.5 \mathrm{hrs}$ of restraint stress caused a similar increase in anxiety-like behaviour, measured 24h later, using the light-dark box (Fig 1C). The canonical stress pathway is necessary for this stress-induced increase in anxiety-like behaviour: inhibiting Cort production, the principal terminal output of the HPA axis, via metyrapone administration (IP; 50mg/kg; 1 h pre-stress) blocked the behavioral changes seen in the WT animals (Fig 1D).

Several studies have reported that acute stress induces TNF expression in the forebrain for up to seven hours (Iwata et al., 2016; Madrigal et al., 2002; Ohgidani et al., 2016; Vecchiarelli et al., 2016), but the role for this persistent elevation remains unclear. In response to forced swim stress, we observed a robust elevation in TNF protein in the ventral hippocampus at $24 \mathrm{~h}$ post-stress (Fig 1E).

To investigate the role of elevated TNF in the initiation or expression of the stress response, we began by comparing circulating Cort levels between wildtype (WT) and TNF deficient (TNF ${ }^{-/}$) mice, both under basal conditions as well as shortly after exposure to acute swim stress. We found no significant differences under either condition (Fig 1F), demonstrating that TNF is not involved in regulating circulating Cort levels basally nor its release following stress. Stress is also known to be a potent activator of immediate early gene expression in the hippocampus (Cullinan et al., 1995). Synaptic output from ventral hippocampus is strongly linked to the expression of anxiety-related behaviours (Jimenez et al., 2018; Padilla-Coreano et al., 2016) and this region is involved in descending regulation of the HPA in response to acute stress (Radley and Sawchenko, 2011). Therefore, we tested whether TNF ${ }^{-}$animals have a normal c-Fos response to stress in the ventral hippocampus. We observed that the stressinduced increase in c-Fos expression was comparable between $T N F^{-/}$and WT animals (Supplemental Fig 1). As a whole, these data suggest Cort regulation is independent of TNF, and thus TNF would more likely be a downstream mediator of the stress response.

To test the role of TNF in the expression of stress-induced behavioral change, we next examined the difference in stress-induced changes in anxiety-like behaviour between WT and TNF-mice. Using the light-dark box, $T N F^{--}$mice spent an equivalent amount of time in the light compartment as their WT counterparts under control conditions but importantly did not show any decrease in this measure following stress (Fig 2A). Mice lacking TNF also did not have the normal anxiety-induced increase in 
latency to enter the light compartment and decrease in transitions between the compartments (Supplemental Fig 2). Similarly, mice lacking the principal receptor for TNF (TNFR1 ${ }^{-1}$ ) also had normal baseline behaviour but no stress-induced elevation in anxiety-like behaviour (Supplemental Fig 3).

The stress-induced elevation in TNF appears to be microglial in origin. Mice with a specific deletion of TNF from astrocytes (using GFAP-Cre combined with floxed TNF alleles) have an equivalent increase in anxiety-like behaviour following stress as their Cre negative littermates (Fig 2B). However, conditional deletion of TNF from microglia using CX3CR1-Cre prevented the increase in anxiety-like behavior in stressed CX3CR1-Cre positive mice relative to their unstressed CX3CR1-Cre expressing littermates, although there was a baseline behavioural shift in these animals (Fig $2 \mathrm{C}$ ). These data were corroborated by the lack of stress-induced elevation of hippocampal TNF in animals lacking microglial TNF (Fig 2D). Consistent with an increase in microglia activation, we also observed a stress-induced increase in IBA1 immunostaining in the ventral hippocampus and a shift to a less polarized microglial morphology (Supplemental Fig 4). We further used RNAscope to label TNF mRNA in sections from the same animals. Analysis of the stratum radiatum of the ventral hippocampus revealed a stress-induced increase in TNF mRNA labeling (Fig 2E-F) as well as an increase in TNF mRNA associated with microglia (Fig 2G). This is consistent with the stress-induced activation of microglia observed previously by others (Calcia et al., 2016; Serrats et al., 2017).

Acute stressors, including forced swim and restraint, have been shown to modify basal glutamatergic transmission in a Cort-dependent manner at several forebrain synapses (Campioni et al., 2009; Yuen et al., 2009; Yuen et al., 2011). We assessed glutamatergic transmission at Schaffer Collateral (SC) to CA1 synapses in the ventral hippocampus. Acute swim stress resulted in an increase in the AMPA/NMDA ratio at the SC synapses on CA1 pyramidal cells, relative to control mice left in their home cages. This potentiation was evident within $2 \mathrm{~h}$ and was sustained for at least $24 \mathrm{~h}$ (Fig 3A and Supplemental Fig 5A). Acute stress has been demonstrated to induce plasticity of AMPA receptor (AMPAR) currents, NMDA receptor (NMDAR) currents, or both, depending on brain structure examined (Campioni et al., 2009; Kuzmiski et al., 2010; Yuen et al., 2009). Given this, we pharmacologically isolated AMPAR or NMDAR currents and assessed stimulus input-current output (I-O) relationships $24 \mathrm{~h}$ following stress. We found that AMPAR-mediated transmission was significantly potentiated (Fig 3B) while there was no significant change in NMDAR-mediated transmission (Fig 3C). Some studies have demonstrated a pre-synaptic locus of expression of enhanced glutamatergic transmission shortly following acute stress (Musazzi et al., 2010; Treccani et al., 2014), but we observed no changes in pre-synaptic glutamate release, as 
measured by the coefficient of variability (CV) and paired pulse ratio (PPR) (Supplemental Fig 5B-C). Since acute stress or glucocorticoid administration have also been shown to alter expression of some intrinsic voltage-gated currents and ion channel subunits (Gray et al., 2014; Joels et al., 2003; Morsink et al., 2007), we also compared basic cellular electrophysiological properties of CA1 pyramidal cells resting membrane potential, membrane resistance, and membrane capacitance - between stress and control groups and found them unchanged (Supplementary Fig 5D-F). This suggests that the observed potentiation of glutamatergic transmission in ventral hippocampal SC to CA1 synapses is principally due to post-synaptic AMPAR trafficking, as has been shown for prefrontal cortex pyramidal cells (Yuen et al., 2011).

We then tested the TNF dependence of this increase in AMPAR-mediated currents. We first determined that basal AMPAR-mediated transmission in the ventral hippocampus was not significantly different between WT and $T N F^{-/}$animals (Supplemental Fig 6A). However, $T N F^{-/}$animals did not show potentiation of AMPAR currents after being exposed to acute stress in vivo; instead AMPAR currents tended to be depressed following stress (Fig 3D). Stress-induced Cort release has generally been assumed to directly drive associated in vivo synaptic changes, in part because ex vivo (Karst and Joels, 2005) or in vitro (Groc et al., 2008; Yuen et al., 2011) application of Cort can potentiate synapses. We therefore tested the ex-vivo Cort response of WT and $T N F^{-/}$hippocampal slices. In marked contrast to the in vivo results, TNF was dispensable for the ex vivo Cort-induced potentiation of AMPAR current at CA1 synapses in the ventral hippocampus (Supplemental Fig 7). This suggests that ex-vivo application of Cort does not replicate the in vivo mechanism, where TNF signaling is required.

To address potential off-target effects stemming from our use of germline $T N F^{-/}$animals, we turned to a pharmacological strategy using the brain-permeant reagent XPro1595, a dominant negative version of TNF (DN-TNF) that antagonizes TNF signaling in a temporally constrained manner (Steed et al., 2003). Pre-administration of DN-TNF (IP; $20 \mathrm{mg} / \mathrm{kg}$ ) prior to exposing WT mice to stress (Fig 4A) completely blocked the subsequent stress-induced potentiation of AMPAR synaptic currents (Fig 4B-C). This was specific to the potentiated synapses since DN-TNF administration under control conditions did not alter basal synaptic transmission (Supplemental Fig 6B). These data indicate that TNF is required during the stress response for the subsequent synaptic changes. As in vivo TNF-mediated synaptic changes are not typically long-lasting (Lewitus et al., 2016; Lewitus et al., 2014), this suggests that persistent TNF signalling might be necessary to maintain the potentiation. To address this, we first tested whether the stress-induced synaptic plasticity could be reversed following the induction and expression of the 
potentiation, which occurs within $2 \mathrm{~h}$ (see Fig $3 \mathrm{~A}$ ). Indeed, we found that administering DN-TNF to animals 5-24h after swim stress (Fig 4D) was sufficient to reverse the stress-induced synaptic potentiation at $48 \mathrm{~h}$ post-stress (Fig $4 \mathrm{E}-\mathrm{F})$.

We then proceeded to test the behavioral consequences of this protocol. As with the synaptic potentiation, administration of DN-TNF $5 \mathrm{~h}$ after swim stress completely abrogated the anxiety-like phenotype seen in the saline treated cohort (Fig 4G). These results were replicable using restraint stress, as administering DN-TNF $5 \mathrm{~h}$ after this stressor also blocked the stress-induced increase in anxiety-like behavior (Fig 4H). This was dependent on TNF signaling within the ventral hippocampus, as local injection of DN-TNF bilaterally into the ventral hippocampus was sufficient to block the expression of stress-induced anxiety-like behavior relative to littermates injected with saline (Fig 4I). Neither stress, drug, nor mode of administration impacted the locomotor behaviour of the animals (Supplemental Fig 8). We therefore conclude that acute stress induces on-going TNF signalling within the ventral hippocampus that is required to maintain the synaptic and behavioral outcomes of the stressor, in particular anxiety-like behaviours.

\section{Discussion}

This TNF-mediated potentiation correlates with the stress-induced increase in anxiety like behavior, and blocking TNF-signaling even hours after the stressor reverses both the synaptic potentiation and anxiety like behavior.

Our results here reveal a novel property of the in vivo stress response, dissecting the response into at least two distinct phases: an induction phase and a maintenance phase. Importantly, we did not observe any gross abnormalities in the neuroendocrine axis of TNF deficient animals, nor in the stress-induced expression of the immediate early gene c-Fos, again highlighting that the deficit these animals exhibit with respect to the stress response appears limited to a lack of expression of a specific form of synaptic plasticity.

The induction phase is likely Cort dependent, as blocking Cort production with metyrapone prevented the stress-induced anxiety. Previous results have also implicated Cort in the synaptic potentiation (Campioni et al., 2009; McEwen et al., 2015; Popoli et al., 2011; Yuen et al., 2009). However, the majority of work suggesting that Cort directly drives the potentiation comes from in vitro application of Cort (Groc et al., 2008; Karst and Joels, 2005; Yuen et al., 2011). While we can replicate the substantial 
potentiation of hippocampal synapses by Cort in vitro (Supplemental Figure 7), other work suggests that this potentiation is not sustained beyond a few hours (Karst and Joels, 2005). Further, slices from TNF ${ }^{-1}$ mice display an equal Cort-driven synaptic potentiation in vitro, but no sustained stress-induced hippocampal potentiation in vivo. Thus we would argue that Cort is necessary to induce the stress response but the sustained synaptic potentiation in vivo is maintained by on-going TNF signaling. Consistent with our findings, TNF can directly increase AMPAR content at CA1 hippocampal synapses (Beattie et al., 2002) and increased output from the ventral hippocampus can drive anxiety-like behavior (Jimenez et al., 2018). Thus TNF is likely to drive the observed synaptic potentiation on CA1 pyramidal neurons, which may well be accompanied by decreased inhibition (Stellwagen et al., 2005), and would result in increased activity of these cells. That blocking TNF signaling just within the ventral hippocampus is sufficient to prevent the stress-induced anxiety would argue that these synaptic changes in the ventral hippocampus are causative for the stress-induced increase in anxiety-like behavior.

Our data here also supports the idea that microglia are the source of the stress-induced elevation in TNF. Consistent with previous reports (Calcia et al., 2016; Ohgidani et al., 2016; Serrats et al., 2017), we observe a stress-induced increase in markers of microglia activation, including increase Iba1 expression and altered microglia morphology. Moreover, we observed an increase in TNF mRNA associated with microglia. The conditional deletion of TNF from microglia prevented the stress-induced increase in hippocampal TNF, and also prevented a stress-induced increase in anxiety-like behavior. However, we did observe a baseline shift in anxiety-like behavior in these mice, which was not seen in either the full TNF knockout or the astrocyte-specific knockout. This complicates the interpretation, and we have observed several changes in baseline behavior in the microglial-conditional mice (including increased aggression and fighting) that could drive other changes in baseline behavior. But despite the baseline shift, there should be adequate potential to express additional anxiety-like behavior as the mice are still spending over $20 \%$ of their time in the light compartment, and thus we don't believe that any floor effect is obscuring a stress-induced change in behavior. Importantly, when combined with the other data on stress-induced microglial activation and lack on TNF response to stress in the conditional mutant, we believe that a microglia source of stress-induced TNF is the most parsimonious hypothesis. Whether the microglial activation is due to Cort signaling is unclear at this point. Our data suggests that Cort signaling is critical for the stress-induced behavioral change, but the direct activation will need to be tested. Microglia express both MR and GR (Brocca et al., 2019; Chantong et al., 2012), and stress can act through GR to increase TNF levels (Frank et al., 2012; Wang et al., 2017). A glial target of Cort 
signaling would be consistent with the finding that conditional deletion of GR from forebrain excitatory neurons did not alter a stress-induced increase in anxiety-like behavior (Furay et al., 2008).

Other cytokines may also be released by activated microglia, and there is evidence that IL1 contributes to stress induced anxiety-like behavior (McKim et al., 2018), although the observed increase in IL1 was more transient than the increase in TNF. This could suggest that multiple cytokines are involved with the induction of the stress response but perhaps TNF has a unique role in maintaining the anxiety.

One interesting observation is the significant decrease in synaptic strength post-stress observed in $T N F^{-1}$ and DN-TNF treated animals, which suggests that the synaptic strength is actually decreasing in response to stress. This might be indication of a countervailing resilience-type signal being unmasked in the absence of TNF signaling, though the nature of such a signal would need to be determined.

Critically, the functional consequences of this stress-induced potentiation can be reversed well after its onset by blocking TNF signaling. The synaptic potentiation is established within $2 \mathrm{~h}$ of the stressor, yet blocking TNF signaling $5 \mathrm{~h}$ afterwards is sufficient to reverse both the synaptic plasticity and the behavioral change. Thus hippocampal TNF signaling is necessary for the maintenance of these changes. This may have therapeutic potential for cases in which the effects of stress are particularly detrimental as in post-traumatic stress disorder, where TNF-based therapeutics may hold potential to treat the chronic anxiety of such conditions. 


\section{Materials and Methods}

All experiments and procedures involving animal use were conducted in accordance with the guidelines of the Canadian Council on Animal Care and approved by the local Animal Care Committee.

\section{Animals}

All experiments were done using adult C57BL/6 male mice, 8-16 week old for behavioral experiments and 8-12 week old for electrophysiology experiments. TNF homozygous knockout (TNF-1) mice, obtained from Jackson Labs, were bred in house, and compared with wild-type (WT) mice of the same background strain (C57BL/6J) also bred in house. The in-house WT and TNF/- lines were periodically backcrossed. In some cases, WT C57BL/6 mice were obtained from Charles River, in which case they were housed in the animal facility for at least one week prior to experimentation. TNFR1\% mice (Peschon et al., 1998) were obtained from Jackson Labs and bred homozygously. Floxed TNF mice were obtained from S. Nedospasov (Grivennikov et al., 2005) and crossed with GFAP-Cre mice (Bajenaru et al., 2002) from NCI Mouse Repository (RRID: IMSR_NCIMR: 01XN3) or with Tg(Cx3cr1-cre)MW126Gsat mice (Yona et al., 2013) generated by N. Heintz (The Rockefeller University, GENSAT) and purchased from MMRRC (UC Davis; RRID: MMRRC_036395-UCD). GFAP or Cx3Cr1-Cre expressing mice were compared with GFAP or CX3CR1-Cre non-expressing littermates. Floxed TNF and GFAP-Cre mice were on a C57BL/6 background; Cx3Cr1-Cre mice were a mix of FVB/B6/129/Swiss/CD1 and backcrossed several generations with $\mathrm{C57BL} / 6 \mathrm{~J}$. Animals were group housed (3-5 animals/cage, except following stress; see below) in standard controlled housing environment of $12 \mathrm{~h}$ light cycle, and food and water available ad libitum.

\section{Stress paradigms}

Two stressors were used to verify the robustness of the phenotype: most animals were exposed to a forced swim of 20 min duration; the time of day in which the animals were exposed to stress was consistent throughout all experiments (10:00 AM - 1:00 PM). Animals were placed in a $4 \mathrm{~L}$ glass beaker, filled to the $3 \mathrm{~L}$ mark with room temperature $\left(23-25^{\circ} \mathrm{C}\right)$ tap water. At completion, excess water was gently wiped off animals and they were housed individually thereafter, with food and water available ad libitum until experimentation. Other animals were exposed to immobilization stress through restraining them in $50 \mathrm{ml}$ conical tubes (Sarstedt \#62.547.205), perforated to allow for airflow. Tubes were then left undisturbed for $1.5 \mathrm{~h}$ at room temperature under regular room white fluorescent lighting conditions. Animals were again individually housed post-stress. There was no significant effect of short-term single 
housing on TNF protein levels in the VHPC (Supplemental Fig 9A) or on anxiety-like behavior (Supplemental Fig 9B), so single-housing does not constitute a significant stressor on its own.

\section{Cannula implantation and local injections}

Bilateral cannulation was performed on 8-week-old mice with a recovering period of three-four weeks to allow inflammation to subside. Animals were administrated an analgesic (Carprofen; SC, $20 \mathrm{mg} / \mathrm{kg}$ ) $2 \mathrm{hr}$ before the surgery then anaesthesia was induced at $3 \%$ isoflurane and maintained at $2 \%$ throughout the surgery. Animals were injected with $1 \mathrm{ml}$ of warm saline at the beginning and the end of the surgery to prevent dehydration and were kept on an active heating pad to reduce anaesthesia induced hypothermia (PhysioSuite, Kent Scientific). Eye lubricant was repeatedly applied throughout the surgery to prevent eye damage. Cannulae were stereotaxically implanted into the ventral hippocampi at coordinates (relative to Bregma) of AP $-3.31 \mathrm{~mm}, \mathrm{ML} \pm 3.47 \mathrm{~mm}$, DV $-4.6 \mathrm{~mm}$; and secured with dental cement.

The skin was closed with braided silk sutures (Medtronic, KENS1173) and cannula caps were placed to prevent clogging. Animals were allowed to recover in heated cages, and administrated Carprofen $(20 \mathrm{mg} / \mathrm{kg} / \mathrm{day})$ for three days. Post-op animals were group housed for 3-4 weeks, and then exposed to $1.5 \mathrm{hr}$ restraint stress and single housed from then on. DN-TNF or saline was administrated $5 \mathrm{hr}$ poststress, using an injection cannula attached to a Hamilton syringe and a micropump at a rate of 0.2 $\mu \mathrm{l} / \mathrm{min}$ to inject $0.625 \mu \mathrm{l}$ in each hemisphere. The injection cannula was then kept in place for 1-2 minutes before removal to prevent backflow. The injection apparatus was checked before and after each injection to ensure proper flow. Animals were returned to their cages and then behaviorally tested $48 \mathrm{hr}$ post-stress. Injection sites were verified by histology to be in the ventral hippocampus for all animals; a representative injection site is show in Supplemental Fig 10.

\section{Electrophysiology}

Synaptic glutamatergic currents were measured from animals that were housed under control conditions or at 2-24 hr post-stress (AMPA/NMDA ratios) or $24 \mathrm{~h}$ post-stress (I/O curves). A few cells for I/O curves were sampled at $2 \mathrm{hr}$ post-stress, but since there was no difference in the potentiation of AMPA/NMDA ratios or AMPAR-mediated currents observed $2 \mathrm{~h}$ and $24 \mathrm{~h}$ post-stress, data from these time points were pooled. Animals were anesthetized by isoflurane inhalation, and rapidly perfused through the left cardiac ventricle with ice-cold solution (composition in mM: glycerol 222, D-glucose 11, $\mathrm{NaHCO}_{3} 26, \mathrm{KCl} 2.5, \mathrm{NaH}_{2} \mathrm{PO} 41.25, \mathrm{MgCl}_{2} 3.5, \mathrm{MgSO}_{4} 1, \mathrm{CaCl}_{2}$ 0.25, Na pyruvate 1.5, Na ascorbate 0.4) pre-saturated with $95 \% \mathrm{O}_{2} / 5 \% \mathrm{CO}_{2}$. The brain was then removed and horizontal slices of 300-400 $\mu \mathrm{m}$, 
containing the ventral hippocampus, were cut on a vibrating slicer (Leica VT1200S) in the same solution used for perfusion, followed by recovery of slices at $32 \pm 2{ }^{\circ} \mathrm{C}$ for $30-45 \mathrm{~min}$ in solution of composition (in mM): $\mathrm{NaCl} 118, \mathrm{D}$-glucose 11, $\mathrm{NaHCO}_{3} 26, \mathrm{KCl} 2.5, \mathrm{HEPES} 15, \mathrm{NaH}_{2} \mathrm{PO}_{4} 1.25, \mathrm{MgSO}_{4} 1, \mathrm{CaCl}_{2} 2$, myoinositol 3, $\mathrm{Na}$ ascorbate 0.4 , saturated with $95 \% \mathrm{O}_{2} / 5 \% \mathrm{CO}_{2}$; slices were maintained at room temperature thereafter, and were only used for experiments after a minimum of $1 \mathrm{~h}$ incubation postslicing.

Immediately prior to placing brain slices in a perfusion chamber on the stage of an upright Olympus microscope (BX51WI) equipped with IR-DIC optics, a cut was made between CA3 and CA1. Using Clampex to run Multiclamp 700 with Digidata 1440 (Molecular Devices), voltage-clamp recordings at holding potential of $-70 \mathrm{mV}$ (unless otherwise specified) were acquired, at $10 \mathrm{kHz}$ sampling with $2 \mathrm{kHz}$ low-pass filtering, from visually identified CA1 pyramidal cells using borosilicate glass pipette electrodes, pulled to produce a resistance of 2-5 $\mathrm{M} \Omega$ when filled with internal solution of composition (in $\mathrm{mM}$ ): $\mathrm{CsMeSO}_{4}$ 125, $\mathrm{CsCl}$ 10, HEPES 15, MgATP 4, Na 3 GTP 0.4, $\mathrm{Na}_{2}$-phosphocreatine 5, Trisphosphocreatine 5, EGTA 0.6, $\mathrm{CaCl}_{2}$ 0.05, pH adjusted to 7.2 with $\mathrm{CsOH}$. Bath solution containing (in $\mathrm{mM}$ ): $\mathrm{NaCl} 110$, Dglucose 11, $\mathrm{NaHCO}_{3} 26, \mathrm{KCl} 2.5, \mathrm{HEPES} 15, \mathrm{NaH}_{2} \mathrm{PO}_{4}$ 1.25, $\mathrm{MgSO}_{4} 1, \mathrm{MgCl}_{2} 3, \mathrm{CaCl}_{2} 4$, myo-inositol 3, and saturated with $95 \% \mathrm{O}_{2} / 5 \% \mathrm{CO}_{2}$ was perfused at a rate of $4-8 \mathrm{~mL} / \mathrm{min}$, and maintained at $30 \pm 2{ }^{\circ} \mathrm{C}$. In all experiments, the bath solution was supplemented with $100 \mu \mathrm{M}$ picrotoxin to block $\mathrm{GABA}_{A} \mathrm{R}$-mediated currents; $50 \mu \mathrm{M}$ D-AP5 was added to isolate AMPAR currents, while $15 \mu \mathrm{M}$ NBQX was added and the holding potential adjusted to $+40 \mathrm{mV}$ to isolate NMDAR currents. To evoke synaptic responses, a stimulus isolator (ISO-FLEX, A.M.P.I.) was used to deliver constant current stimuli (0.1 ms pulse duration) to stratum radiatum, using either a chlorided silver wire housed in a glass pipette filled with bath solution, or, in the case of obtaining input-output relationships, matrix electrodes fabricated by FHC $(\mathrm{MX21AES}(\mathrm{DH} 1))$. Care was taken in the case of obtaining input-output relationships to systematically place the stimulating electrode within $\sim 20 \mu \mathrm{m}$ of the cell being recorded, and control condition recordings were consistently interleaved throughout the period of experimentation. Stimuli were delivered at intervals of 5-15 s, and 6-30 sweeps were averaged for any given stimulus level (using Clampfit 10). AMPA/NMDA ratios were obtained by dividing the peak of the evoked current generated while the cell is held at $-70 \mathrm{mV}$ by the mean level of the current $50 \mathrm{~ms}$ from the onset of stimulus while the cell is held at $+40 \mathrm{mV}$. Alternatively, a subset of cells was perfused with $50 \mu \mathrm{M}$ D-AP5 while held at $+40 \mathrm{mV}$, and the resultant isolated AMPAR current obtained following D-AP5 perfusion was subtracted from the compound current prior to perfusion with D-AP5 to obtain the NMDAR component of the 
evoked response, in which case the peak of the AMPAR current was divided by the peak of the resultant NMDAR current.

\section{Drug treatments}

For experiments involving corticosterone treatment, corticosterone stock prepared in DMSO was diluted to $100 \mathrm{nM}$ and applied to brain slices in the solution used for recovery from vibratome slicing, for $20 \mathrm{~min}$ at $30 \pm 2{ }^{\circ} \mathrm{C}$, with constant aeration with $95 \% \mathrm{O}_{2} / 5 \% \mathrm{CO}_{2}$. Slices were then washed with corticosteronefree solution, and then incubated in slice recovery solution. Voltage-clamp recordings were obtained between 2-3 $\mathrm{h}$ following corticosterone treatment. Controls were likewise treated, but with vehicle (0.01\% v/v DMSO). Metyrapone was obtained from Tocris Bioscience \#3292/50 and reconstituted to 23 $\mathrm{mg} / \mathrm{ml}$ with DMSO and administrated intraperitoneally at a final doze of $50 \mathrm{mg} / \mathrm{kg}$. TNF dominantnegative inhibitor XPro1595 (DN-TNF; Xencor, Inc.) was diluted in sterile $0.9 \% \mathrm{w} / \mathrm{v} \mathrm{NaCl}$ to $2 \mathrm{mg} / \mathrm{mL}$ (intraperitoneal injection) or $5 \mathrm{mg} / \mathrm{ml}$ (direct injection into the hippocampi) and administered at a dose of $20 \mathrm{mg} / \mathrm{kg}$. Controls were administered equivalent volumes of DMSO or sterile saline $0.9 \% \mathrm{w} / \mathrm{v} \mathrm{NaCl}$, respectively.

\section{Cort ELISA}

Stress-induced serum corticosterone measures were obtained 15 min following completion of forced swim protocol. Animals were anesthetized by isoflurane inhalation, decapitated, and trunk blood collected in polypropylene centrifuge tubes. Samples were stored at room temperature for $1.5 \mathrm{~h}$ to allow for clot formation, followed by centrifugation $(300 \times \mathrm{g})$ to collect supernatant for storage at $-80^{\circ} \mathrm{C}$ until assayed. An ELISA kit from Cayman for corticosterone was used according to the suppliers' instructions. Samples were diluted 100 -fold prior to measurement.

\section{TNF ELISA}

Bilateral ventral hippocampal tissue was collected from stressed animals ( 24 hours post forced swim stress) and their age matched unstressed controls. They were anesthetized by isoflurane inhalation and decapitated for a rapid removal of the brain and gross dissection of the ventral hippocampi (<1 min). Tissue was then snap-frozen in liquid nitrogen. Tissue was then immediately homogenized using a handheld homogenizer for 5 seconds on ice in $400 \mu$ l of sterile PBS buffer containing a 1x protease inhibitor cocktail from Bioshop (PIC002.1). Samples were then centrifuged at 11,000 rpm for 20 minutes at $4{ }^{\circ} \mathrm{C}$ and the supernatants collected. TNF protein levels were measured according to the suppliers' instructions of mouse TNF ELISA kit (eBioscience, Mouse TNF alpha ELISA Ready-SET-Go! Kit \#88-7324). For standardization across samples, all TNF concentrations were divided by their corresponding crude- 
protein input concentrations as measured following the instructions of the bicinchoninic acid assay (BCA) kit from Thermo Fisher Scientific (\#23227).

c-Fos Immunohistochemistry

One hour following stress, animals were anesthetized by isoflurane inhalation, followed by transcardial perfusion with $4 \% \mathrm{w} / \mathrm{v}$ formaldehyde in PBS. The brain was then dissected and immersed in $4 \% \mathrm{w} / \mathrm{v}$ formaldehyde for $24 \mathrm{~h}$ at $4{ }^{\circ} \mathrm{C}$, then transferred to $30 \% \mathrm{w} / \mathrm{v}$ sucrose solution. The brains were subsequently mounted in Optimal Cutting Temperature (OCT) medium to cut $30 \mu \mathrm{m}$ slices using cryostat microtome. Slices were incubated in a blocking solution, composition: $2 \% \mathrm{v} / \mathrm{v}$ normal goat serum and $1 \%$ $\mathrm{v} / \mathrm{v}$ affinipure donkey anti-mouse IgG (Jackson Immunoresearch) in PBS for $4 \mathrm{~h}$ at room temperature. Slices were subsequently incubated with primary antibodies: anti-c-Fos at 1:100 dilution (Santa Cruz Biotechnology, catalogue sc-52) and anti-NeuN at 1:200 (Millipore, catalogue MAB377) in blocking solution overnight at $4{ }^{\circ} \mathrm{C}$. Slices were then washed twice (15 min each wash) with PBS $+0.05 \%$ Tween 20 (PBST), and once in PBS for $15 \mathrm{~min}$, and incubated with secondary antibodies: Alexa568-conjugated anti-rabbit IgG at 1:300 dilution and Alexa488-conjugated anti-mouse IgG at 1:400 dilution in blocking buffer for $2 \mathrm{~h}$ at room temperature. Slices were then washed twice (15 min each wash) with PBS $+0.05 \%$ Tween 20 (PBST), and once in PBS for 15 min, followed by mounting in Fluoromount-G medium (Southern Biotech). Images were acquired with an Olympus Fluoview FV1000 confocal microscope using 20X objective. 25-30 optical sections at $1 \mu \mathrm{m}$ optical sectioning were collected, and Z-projected into a single image. Multiple images of region CA1 and DG were collected for each animal, and the number of c-Fos immunoreactive cells were manually counted, and averaged for all slices to give one mean value for each animal. For clarity, the c-Fos-labeled sections used as example images shown were background subtracted and despeckled using Image $(\mathrm{NIH})$, followed by conversion to binary format and dilation, and then overlaid with corresponding NeuN-labeled sections.

\section{IBA1 Immunohistochemistry and microglial analysis}

Animals were perfused $4 \mathrm{hr}$ post-restraint stress with 4\% PFA in PBS, and whole brains post-fixed overnight ( $16 \mathrm{hr}$ ) before being cryoprotected in 30\% sucrose in PBS for $4 \mathrm{hr}$. Coronal $25 \mu \mathrm{m}$ sections containing the ventral hippocampus were cut on a cryostat, mounted on charged slides (Fisher Scientific, catalogue 12-550-15) and dried in a desiccating chamber at room temperature for $2 \mathrm{hr}$. Sections were then washed $3 x$ with PBS at room temperature $(10 \mathrm{~min})$ followed by $1 \mathrm{~h}$ permeabilization using $2 \%$ triton X-100 in PBS. Sections were blocked for $2 \mathrm{hr}$ with $10 \%$ normal goat serum, 2\% BSA and 0.3\% Triton $\mathrm{X}-100$, and then incubated overnight at $4^{\circ} \mathrm{C}$ with IBA1 polyclonal rabbit antibody (FUJIFILM Wako 
Chemicals, catalogue 019-19741; 1:500) in blocking buffer. Sections were then washed as before and incubated in goat anti-rabbit secondary antibody (Thermofisher, A21244), washed 4x, and nuclei counterstained with 1:10000 of Hoechst 33342 (Thermofisher H1399) before mounting with Fluoromount-G (Thermofisher, 00-4958-02). Stacked Images were acquired using FV1000 Olympus confocal microscope using 20x objectives of the vCA1 region, with multiple images per animal. Images were then analyzed for signal intensity, cell count and morphology semi-automatically using ImageJ $(\mathrm{NIH})$ and its associated FracLac package (Karperien). Average values were calculated per field, with the researcher blinded during both acquisition and analysis. The images were converted to grayscale, unsharpened, despeckled, thresholded automatically and converted to a binary mask. The "analyze particles" function was then applied with size thresholding of 50 pixels on the lower limit. The obtained ROIs were then checked manually for accuracy then were overlayed over the original image to obtain the reported outputs. Microglia morphology was evaluated using a hull and circle analysis, by fitting each microglia with an encompassing oval/circle and a convex hull. Morphology was then assessed by measuring the polarity of these shapes as a ratio of the major and minor axes and hull circularity as the hull area over the perimeter, with a loss of polarity representing an increase in activation.

\section{Behavior}

All behaviour experiments were verified using multiple cohorts and replicated across different time intervals. Animals were tested 24-48 $\mathrm{h}$ following stress, and experiments were conducted between 10:00 AM and 5:00 PM (anxiety) or 4:00-7:00 PM (locomotion). Anxiety-related behavior was assessed using the Light-Dark box, which consisted of an uncovered compartment (light compartment) made of clear plexiglass, measuring $29 \mathrm{~cm}$ length $\times 20.4 \mathrm{~cm}$ width $\times 22 \mathrm{~cm}$ height, connected via a small box-floor level opening to a black, lid-covered compartment (dark compartment) measuring $15.5 \mathrm{~cm}$ length $\times 20.4$ $\mathrm{cm}$ width $\times 22 \mathrm{~cm}$ height. The animal was placed in the dark compartment with the animal allowed to freely explore both compartments for a period of $10 \mathrm{~min}$ while video recording from directly above. The test was conducted under normal room white fluorescent lighting. The total time spent in the light compartment was scored semi-automatically using Ethovision XT 8.5 (Noldus). Anxiety-like behavior was also assessed using the Open Field Test using a $60 \times 60 \mathrm{~cm}$ clear plexiglass box under normal room lighting conditions. The time spent in the center (out of the total testing time of $10 \mathrm{~min}$ ) was quantified automatically using the pre-existing template in Ethovision. For assessing locomotion, proxied by the total distance travelled during a period of $20 \mathrm{~min}$, animals were placed individually in $30 \times 30 \mathrm{~cm}$ plexiglass boxes recorded from above under low intensity red light conditions. The total distance travelled during the 20 min period was then recorded automatically using Ethovision. 


\section{Statistical analysis}

All data are presented as means \pm SEM. In electrophysiology data, $n$ represents the number of cells, while $\mathrm{N}$ represents the number of animals; no more than three cells were recorded from any given animal, with all experimental groups being represented by at least three animals. Statistical analyses were done using Graphpad Prism 9. Data was analyzed using one or two way ANOVAs, followed by Tukey post-hoc tests, or by Student's unpaired two-tailed t-tests. For Fig 3A, the data was not normally distributed, so we used a Kruskal-Wallis One Way ANOVA on Ranks followed by Dunn's method of comparison with control. 


\section{References}

Bajenaru, M.L., Zhu, Y., Hedrick, N.M., Donahoe, J., Parada, L.F., and Gutmann, D.H. (2002). Astrocytespecific inactivation of the neurofibromatosis 1 gene (NF1) is insufficient for astrocytoma formation. Mol Cell Biol 22, 5100-5113.

Bannerman, D.M., Deacon, R.M., Offen, S., Friswell, J., Grubb, M., and Rawlins, J.N. (2002). Double dissociation of function within the hippocampus: spatial memory and hyponeophagia. Behav Neurosci 116, 884-901.

Beattie, E.C., Stellwagen, D., Morishita, W., Bresnahan, J.C., Ha, B.K., Von Zastrow, M., Beattie, M.S., and Malenka, R.C. (2002). Control of synaptic strength by glial TNFalpha. Science 295, 2282-2285.

Brewin, C.R. (2005). Risk factor effect sizes in PTSD: what this means for intervention. J Trauma Dissociation 6, 123-130.

Brocca, M.E., Pietranera, L., de Kloet, E.R., and De Nicola, A.F. (2019). Mineralocorticoid Receptors, Neuroinflammation and Hypertensive Encephalopathy. Cell Mol Neurobiol 39, 483-492.

Calcia, M.A., Bonsall, D.R., Bloomfield, P.S., Selvaraj, S., Barichello, T., and Howes, O.D. (2016). Stress and neuroinflammation: a systematic review of the effects of stress on microglia and the implications for mental illness. Psychopharmacology 233, 1637-1650.

Camara, M.L., Corrigan, F., Jaehne, E.J., Jawahar, M.C., Anscomb, H., and Baune, B.T. (2015). Effects of centrally administered etanercept on behavior, microglia, and astrocytes in mice following a peripheral immune challenge. Neuropsychopharmacology : official publication of the American College of Neuropsychopharmacology 40, 502-512.

Campioni, M.R., Xu, M., and McGehee, D.S. (2009). Stress-induced changes in nucleus accumbens glutamate synaptic plasticity. J Neurophysiol 101, 3192-3198.

Caso, J.R., Lizasoain, I., Lorenzo, P., Moro, M.A., and Leza, J.C. (2006). The role of tumor necrosis factoralpha in stress-induced worsening of cerebral ischemia in rats. Neuroscience 142, 59-69.

Chantong, B., Kratschmar, D.V., Nashev, L.G., Balazs, Z., and Odermatt, A. (2012). Mineralocorticoid and glucocorticoid receptors differentially regulate NF-kappaB activity and pro-inflammatory cytokine production in murine BV-2 microglial cells. J Neuroinflammation 9, 260.

Chen, J., Song, Y., Yang, J., Zhang, Y., Zhao, P., Zhu, X.J., and Su, H.C. (2013). The contribution of TNFalpha in the amygdala to anxiety in mice with persistent inflammatory pain. Neuroscience letters.

Costa-Pinto, F.A., and Palermo-Neto, J. (2010). Neuroimmune interactions in stress.

Neuroimmunomodulation 17, 196-199.

Cullinan, W.E., Herman, J.P., Battaglia, D.F., Akil, H., and Watson, S.J. (1995). Pattern and time course of immediate early gene expression in rat brain following acute stress. Neuroscience 64, 477-505.

Dhabhar, F.S. (2009). Enhancing versus suppressive effects of stress on immune function: implications for immunoprotection and immunopathology. Neuroimmunomodulation 16, 300-317.

Fanselow, M.S., and Dong, H.W. (2010). Are the dorsal and ventral hippocampus functionally distinct structures? Neuron 65, 7-19.

Felix-Ortiz, A.C., Beyeler, A., Seo, C., Leppla, C.A., Wildes, C.P., and Tye, K.M. (2013). BLA to vHPC inputs modulate anxiety-related behaviors. Neuron 79, 658-664.

Fourrier, C., Bosch-Bouju, C., Boursereau, R., Sauvant, J., Aubert, A., Capuron, L., Ferreira, G., Laye, S., and Castanon, N. (2019). Brain tumor necrosis factor-alpha mediates anxiety-like behavior in a mouse model of severe obesity. Brain, behavior, and immunity 77, 25-36.

Frank, M.G., Thompson, B.M., Watkins, L.R., and Maier, S.F. (2012). Glucocorticoids mediate stressinduced priming of microglial pro-inflammatory responses. Brain, behavior, and immunity 26, 337-345. Furay, A.R., Bruestle, A.E., and Herman, J.P. (2008). The role of the forebrain glucocorticoid receptor in acute and chronic stress. Endocrinology 149, 5482-5490. 
Goshen, I., Kreisel, T., Ben-Menachem-Zidon, O., Licht, T., Weidenfeld, J., Ben-Hur, T., and Yirmiya, R. (2008). Brain interleukin-1 mediates chronic stress-induced depression in mice via adrenocortical activation and hippocampal neurogenesis suppression. Mol Psychiatry 13, 717-728.

Gray, J.D., Rubin, T.G., Hunter, R.G., and McEwen, B.S. (2014). Hippocampal gene expression changes underlying stress sensitization and recovery. Mol Psychiatry 19, 1171-1178.

Grivennikov, S.I., Tumanov, A.V., Liepinsh, D.J., Kruglov, A.A., Marakusha, B.I., Shakhov, A.N., Murakami, T., Drutskaya, L.N., Forster, I., Clausen, B.E., et al. (2005). Distinct and nonredundant in vivo functions of TNF produced by t cells and macrophages/neutrophils: protective and deleterious effects. Immunity 22, 93-104.

Groc, L., Choquet, D., and Chaouloff, F. (2008). The stress hormone corticosterone conditions AMPAR surface trafficking and synaptic potentiation. Nature neuroscience 11, 868-870.

Haji, N., Mandolesi, G., Gentile, A., Sacchetti, L., Fresegna, D., Rossi, S., Musella, A., Sepman, H., Motta, C., Studer, V., et al. (2012). TNF-alpha-mediated anxiety in a mouse model of multiple sclerosis. Exp Neurol 237, 296-303.

Hou, R., Garner, M., Holmes, C., Osmond, C., Teeling, J., Lau, L., and Baldwin, D.S. (2017). Peripheral inflammatory cytokines and immune balance in Generalised Anxiety Disorder: Case-controlled study. Brain, behavior, and immunity 62, 212-218.

Iwata, M., Ota, K.T., Li, X.Y., Sakaue, F., Li, N., Dutheil, S., Banasr, M., Duric, V., Yamanashi, T., Kaneko, K., et al. (2016). Psychological Stress Activates the Inflammasome via Release of Adenosine Triphosphate and Stimulation of the Purinergic Type 2X7 Receptor. Biological psychiatry 80, 12-22.

Jimenez, J.C., Su, K., Goldberg, A.R., Luna, V.M., Biane, J.S., Ordek, G., Zhou, P., Ong, S.K., Wright, M.A., Zweifel, L., et al. (2018). Anxiety Cells in a Hippocampal-Hypothalamic Circuit. Neuron 97, 670-683 e676. Joels, M., Velzing, E., Nair, S., Verkuyl, J.M., and Karst, H. (2003). Acute stress increases calcium current amplitude in rat hippocampus: temporal changes in physiology and gene expression. The European journal of neuroscience 18, 1315-1324.

Karperien, A. (1999-2013.). FracLac for ImageJ. .

Karst, H., and Joels, M. (2005). Corticosterone slowly enhances miniature excitatory postsynaptic current amplitude in mice CA1 hippocampal cells. J Neurophysiol 94, 3479-3486.

Kheirbek, M.A., Drew, L.J., Burghardt, N.S., Costantini, D.O., Tannenholz, L., Ahmari, S.E., Zeng, H., Fenton, A.A., and Hen, R. (2013). Differential control of learning and anxiety along the dorsoventral axis of the dentate gyrus. Neuron 77, 955-968.

Kjaerby, C., Athilingam, J., Robinson, S.E., lafrati, J., and Sohal, V.S. (2016). Serotonin 1B Receptors Regulate Prefrontal Function by Gating Callosal and Hippocampal Inputs. Cell Rep 17, 2882-2890. Kjelstrup, K.G., Tuvnes, F.A., Steffenach, H.A., Murison, R., Moser, E.I., and Moser, M.B. (2002). Reduced fear expression after lesions of the ventral hippocampus. Proceedings of the National Academy of Sciences of the United States of America 99, 10825-10830.

Koo, J.W., and Duman, R.S. (2008). IL-1beta is an essential mediator of the antineurogenic and anhedonic effects of stress. Proceedings of the National Academy of Sciences of the United States of America 105, 751-756.

Kuzmiski, J.B., Marty, V., Baimoukhametova, D.V., and Bains, J.S. (2010). Stress-induced priming of glutamate synapses unmasks associative short-term plasticity. Nature neuroscience 13, 1257-1264. Lewitus, G.M., Konefal, S.C., Greenhalgh, A.D., Pribiag, H., Augereau, K., and Stellwagen, D. (2016). Microglial TNF-alpha Suppresses Cocaine-Induced Plasticity and Behavioral Sensitization. Neuron 90, 483-491.

Lewitus, G.M., Pribiag, H., Duseja, R., St-Hilaire, M., and Stellwagen, D. (2014). An adaptive role of TNFalpha in the regulation of striatal synapses. J Neurosci 34, 6146-6155.

Madrigal, J.L., Hurtado, O., Moro, M.A., Lizasoain, I., Lorenzo, P., Castrillo, A., Bosca, L., and Leza, J.C. (2002). The increase in TNF-alpha levels is implicated in NF-kappaB activation and inducible nitric oxide 
synthase expression in brain cortex after immobilization stress. Neuropsychopharmacology : official publication of the American College of Neuropsychopharmacology 26, 155-163.

McEwen, B.S., Bowles, N.P., Gray, J.D., Hill, M.N., Hunter, R.G., Karatsoreos, I.N., and Nasca, C. (2015). Mechanisms of stress in the brain. Nature neuroscience 18, 1353-1363.

McKim, D.B., Weber, M.D., Niraula, A., Sawicki, C.M., Liu, X., Jarrett, B.L., Ramirez-Chan, K., Wang, Y., Roeth, R.M., Sucaldito, A.D., et al. (2018). Microglial recruitment of IL-1beta-producing monocytes to brain endothelium causes stress-induced anxiety. Mol Psychiatry 23, 1421-1431.

Morsink, M.C., Van Gemert, N.G., Steenbergen, P.J., Joels, M., De Kloet, E.R., and Datson, N.A. (2007). Rapid glucocorticoid effects on the expression of hippocampal neurotransmission-related genes. Brain research 1150, 14-20.

Musazzi, L., Milanese, M., Farisello, P., Zappettini, S., Tardito, D., Barbiero, V.S., Bonifacino, T., Mallei, A., Baldelli, P., Racagni, G., et al. (2010). Acute stress increases depolarization-evoked glutamate release in the rat prefrontal/frontal cortex: the dampening action of antidepressants. PloS one 5, e8566.

Muscatell, K.A., Dedovic, K., Slavich, G.M., Jarcho, M.R., Breen, E.C., Bower, J.E., Irwin, M.R., and Eisenberger, N.I. (2015). Greater amygdala activity and dorsomedial prefrontal-amygdala coupling are associated with enhanced inflammatory responses to stress. Brain, behavior, and immunity 43, 46-53. Nguyen, K.T., Deak, T., Owens, S.M., Kohno, T., Fleshner, M., Watkins, L.R., and Maier, S.F. (1998). Exposure to acute stress induces brain interleukin-1beta protein in the rat. J Neurosci 18, 2239-2246. O'Connor, K.A., Johnson, J.D., Hansen, M.K., Wieseler Frank, J.L., Maksimova, E., Watkins, L.R., and Maier, S.F. (2003). Peripheral and central proinflammatory cytokine response to a severe acute stressor. Brain research 991, 123-132.

Ohgidani, M., Kato, T.A., Sagata, N., Hayakawa, K., Shimokawa, N., Sato-Kasai, M., and Kanba, S. (2016). TNF-alpha from hippocampal microglia induces working memory deficits by acute stress in mice. Brain, behavior, and immunity 55, 17-24.

Padilla-Coreano, N., Bolkan, S.S., Pierce, G.M., Blackman, D.R., Hardin, W.D., Garcia-Garcia, A.L., Spellman, T.J., and Gordon, J.A. (2016). Direct Ventral Hippocampal-Prefrontal Input Is Required for Anxiety-Related Neural Activity and Behavior. Neuron 89, 857-866.

Parfitt, G.M., Nguyen, R., Bang, J.Y., Aqrabawi, A.J., Tran, M.M., Seo, D.K., Richards, B.A., and Kim, J.C. (2017). Bidirectional Control of Anxiety-Related Behaviors in Mice: Role of Inputs Arising from the Ventral Hippocampus to the Lateral Septum and Medial Prefrontal Cortex. Neuropsychopharmacology : official publication of the American College of Neuropsychopharmacology 42, 1715-1728.

Peschon, J.J., Torrance, D.S., Stocking, K.L., Glaccum, M.B., Otten, C., Willis, C.R., Charrier, K., Morrissey, P.J., Ware, C.B., and Mohler, K.M. (1998). TNF receptor-deficient mice reveal divergent roles for p55 and p75 in several models of inflammation. J Immunol 160, 943-952.

Popoli, M., Yan, Z., McEwen, B.S., and Sanacora, G. (2011). The stressed synapse: the impact of stress and glucocorticoids on glutamate transmission. Nature reviews Neuroscience 13, 22-37.

Qing, H., Desrouleaux, R., Israni-Winger, K., Mineur, Y.S., Fogelman, N., Zhang, C., Rashed, S., Palm, N.W., Sinha, R., Picciotto, M.R., et al. (2020). Origin and Function of Stress-Induced IL-6 in Murine Models. Cell 182, 372-387 e314.

Radley, J.J., and Sawchenko, P.E. (2011). A common substrate for prefrontal and hippocampal inhibition of the neuroendocrine stress response. J Neurosci 31, 9683-9695.

Serrats, J., Grigoleit, J.S., Alvarez-Salas, E., and Sawchenko, P.E. (2017). Pro-inflammatory immune-tobrain signaling is involved in neuroendocrine responses to acute emotional stress. Brain, behavior, and immunity 62, 53-63.

Slavish, D.C., Graham-Engeland, J.E., Smyth, J.M., and Engeland, C.G. (2015). Salivary markers of inflammation in response to acute stress. Brain, behavior, and immunity 44, 253-269.

Sorrells, S.F., Caso, J.R., Munhoz, C.D., and Sapolsky, R.M. (2009). The stressed CNS: when glucocorticoids aggravate inflammation. Neuron 64, 33-39. 
Steed, P.M., Tansey, M.G., Zalevsky, J., Zhukovsky, E.A., Desjarlais, J.R., Szymkowski, D.E., Abbott, C., Carmichael, D., Chan, C., Cherry, L., et al. (2003). Inactivation of TNF signaling by rationally designed dominant-negative TNF variants. Science 301, 1895-1898.

Stellwagen, D., Beattie, E.C., Seo, J.Y., and Malenka, R.C. (2005). Differential regulation of AMPA receptor and GABA receptor trafficking by tumor necrosis factor-alpha. J Neurosci 25, 3219-3228. Stellwagen, D., and Malenka, R.C. (2006). Synaptic scaling mediated by glial TNF-alpha. Nature 440, 1054-1059.

Strange, B.A., Witter, M.P., Lein, E.S., and Moser, E.I. (2014). Functional organization of the hippocampal longitudinal axis. Nature reviews Neuroscience 15, 655-669.

Tang, Z., Ye, G., Chen, X., Pan, M., Fu, J., Fu, T., Liu, Q., Gao, Z., Baldwin, D.S., and Hou, R. (2018). Peripheral proinflammatory cytokines in Chinese patients with generalised anxiety disorder. J Affect Disord 225, 593-598.

Treccani, G., Musazzi, L., Perego, C., Milanese, M., Nava, N., Bonifacino, T., Lamanna, J., Malgaroli, A., Drago, F., Racagni, G., et al. (2014). Stress and corticosterone increase the readily releasable pool of glutamate vesicles in synaptic terminals of prefrontal and frontal cortex. Mol Psychiatry 19, 433-443. Turnbull, A.V., and Rivier, C.L. (1999). Regulation of the hypothalamic-pituitary-adrenal axis by cytokines: actions and mechanisms of action. Physiol Rev 79, 1-71.

Vecchiarelli, H.A., Gandhi, C.P., Gray, J.M., Morena, M., Hassan, K.I., and Hill, M.N. (2016). Divergent responses of inflammatory mediators within the amygdala and medial prefrontal cortex to acute psychological stress. Brain, behavior, and immunity 51, 70-91.

Wang, N., Ma, H., Li, Z., Gao, Y., Cao, X., Jiang, Y., Zhou, Y., and Liu, S. (2017). Chronic unpredictable stress exacerbates surgery-induced sickness behavior and neuroinflammatory responses via glucocorticoids secretion in adult rats. PloS one 12, e0183077.

Wohleb, E.S., Hanke, M.L., Corona, A.W., Powell, N.D., Stiner, L.M., Bailey, M.T., Nelson, R.J., Godbout, J.P., and Sheridan, J.F. (2011). beta-Adrenergic receptor antagonism prevents anxiety-like behavior and microglial reactivity induced by repeated social defeat. J Neurosci 31, 6277-6288.

Wu, M.V., and Hen, R. (2014). Functional dissociation of adult-born neurons along the dorsoventral axis of the dentate gyrus. Hippocampus 24, 751-761.

Yona, S., Kim, K.W., Wolf, Y., Mildner, A., Varol, D., Breker, M., Strauss-Ayali, D., Viukov, S., Guilliams, M., Misharin, A., et al. (2013). Fate mapping reveals origins and dynamics of monocytes and tissue macrophages under homeostasis. Immunity 38, 79-91.

You, Z., Luo, C., Zhang, W., Chen, Y., He, J., Zhao, Q., Zuo, R., and Wu, Y. (2011). Pro- and antiinflammatory cytokines expression in rat's brain and spleen exposed to chronic mild stress: involvement in depression. Behav Brain Res 225, 135-141.

Yuen, E.Y., Liu, W., Karatsoreos, I.N., Feng, J., McEwen, B.S., and Yan, Z. (2009). Acute stress enhances glutamatergic transmission in prefrontal cortex and facilitates working memory. Proceedings of the National Academy of Sciences of the United States of America 106, 14075-14079.

Yuen, E.Y., Liu, W., Karatsoreos, I.N., Ren, Y., Feng, J., McEwen, B.S., and Yan, Z. (2011). Mechanisms for acute stress-induced enhancement of glutamatergic transmission and working memory. Mol Psychiatry $16,156-170$. 


\section{Figure 1}

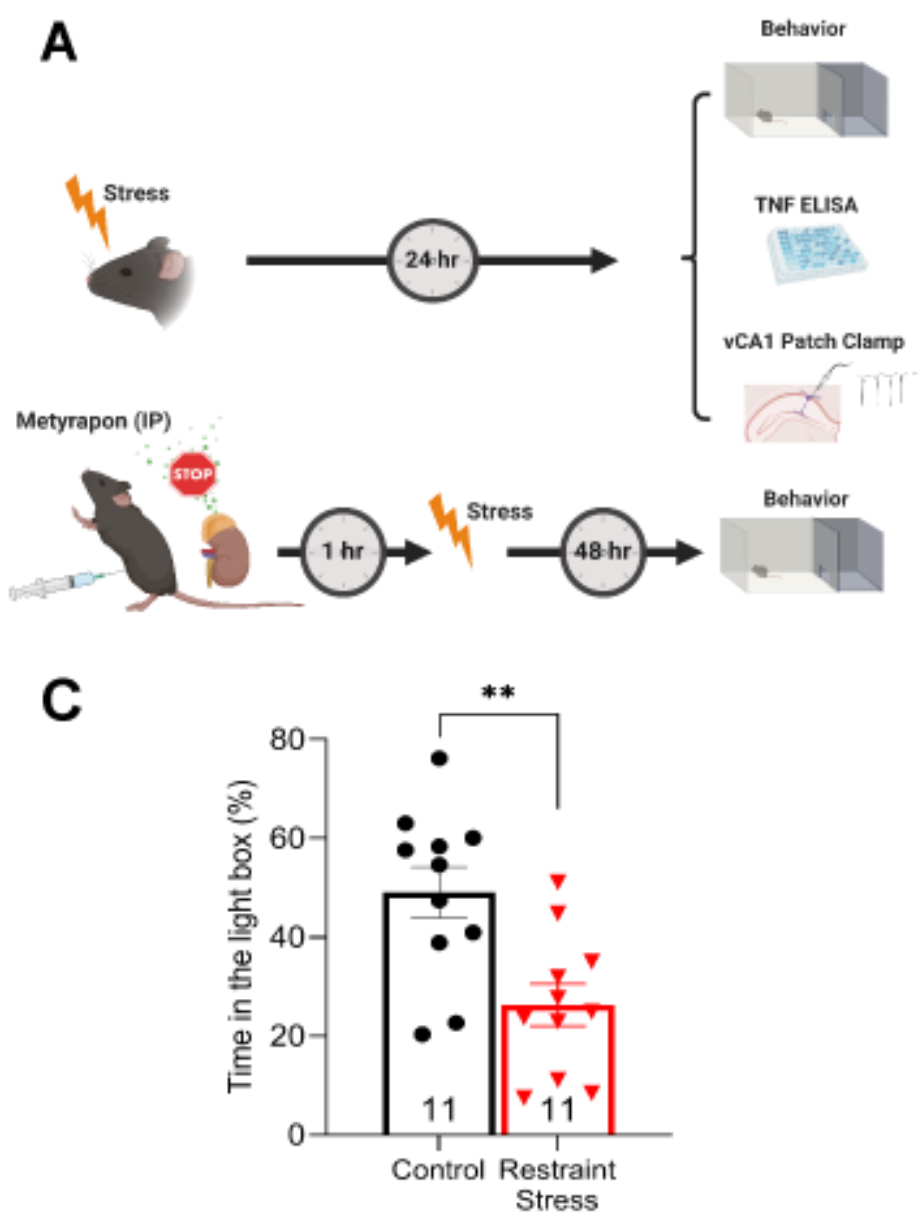

B

- Control $\nabla$ Forced Swim Stress

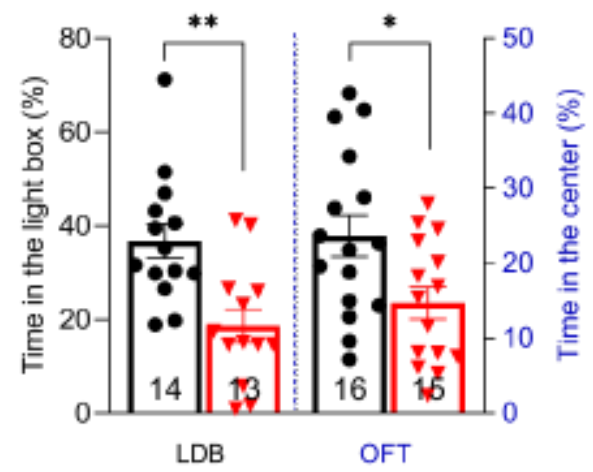

E
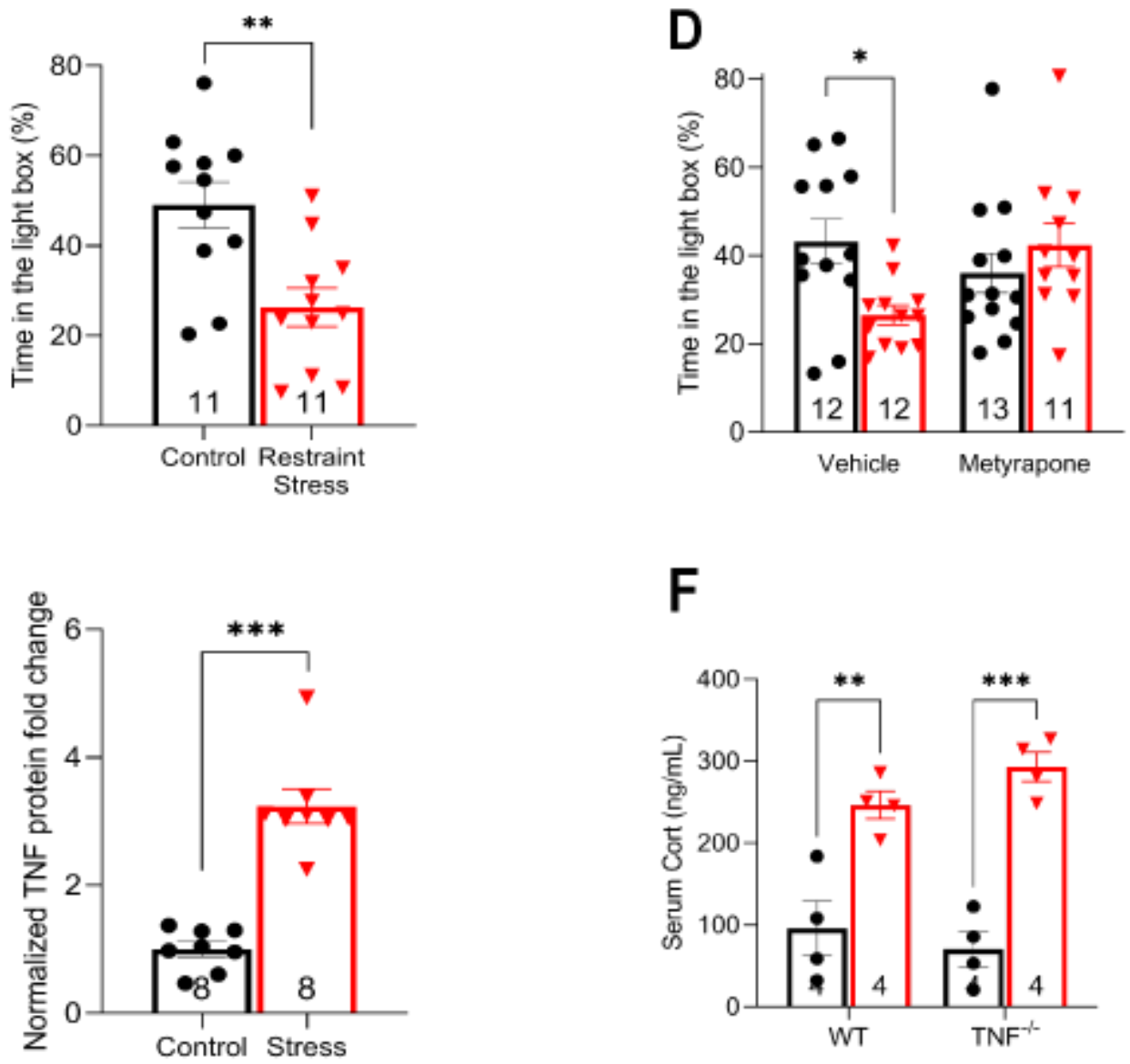

F

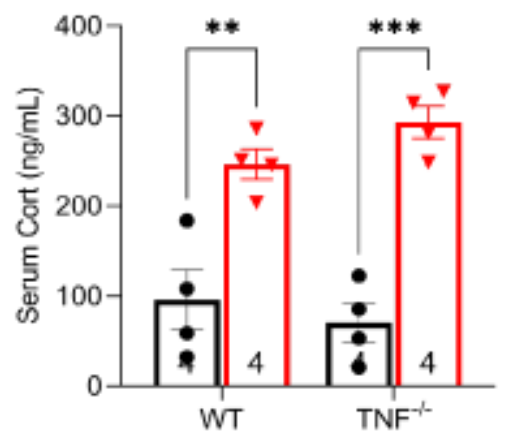




\section{Figure 1: Molecular and behavioral characterization of acutely stressed mice}

A. A general schematic of the conducted experiments. For most experiments, mice were subjected to a single bout of acute stress and tested $24 \mathrm{~h}$ later. Some mice were given metyrapone $1 \mathrm{~h}$ prior to stress and then tested $48 \mathrm{~h}$ later.

B. Animals subjected to forced swim stress display anxiety like behavior, as measured in the LDB (two-tailed student t-test $\mathrm{P}=0.0015$ ) and the OFT (two-tailed student t-test $\mathrm{P}=0.0171$ ).

C. The induction of anxiety-like behavior in males is also observed in response to RS paradigm (two-tailed student t-test, $\mathrm{P}=0.0028$ ).

D. Blocking CORT synthesis through administering metyrapone (IP; $40 \mathrm{mg} / \mathrm{kg}$; $1 \mathrm{~h}$ pre-stress) inhibits stress-induced anxiety-like behavior (significant interaction of stress $\mathrm{x}$ drug; two-way ANOVA F $(1,44)=7.051, \mathrm{P}=0.0110$; Tukey's post hoc analysis of control versus stress within vehicle $\mathrm{P}=0.0444$, within metyrapone $\mathrm{P}=0.7281$ ).

E. Acute swim stress induces significant induction of TNF protein in the vHPC measured $24 \mathrm{~h}$ post-stress $(\mathrm{P}<0.0001)$.

F. Swim stress induces serum CORT levels independent of TNF signaling (ANOVA F $(1,12)=$ 63.79, $\mathrm{P}<0.0001$; Tukey's post hoc analysis of control versus stress within WT animals $\mathrm{P}=$ 0.0031 , within $\mathrm{TNF}^{-/-}$animals $\mathrm{P}=0.0001$ )

$* \mathrm{P}<0.05, * * \mathrm{P}<0.01, * * * \mathrm{P}<0.001$. Data are presented as mean $\pm \mathrm{SEM}$. TNF, tumor necrosis factor; CORT, corticosterone; LDB, light-dark box. OFT; open field test. Sample sizes are indicated on the figures. 


\section{Figure 2}

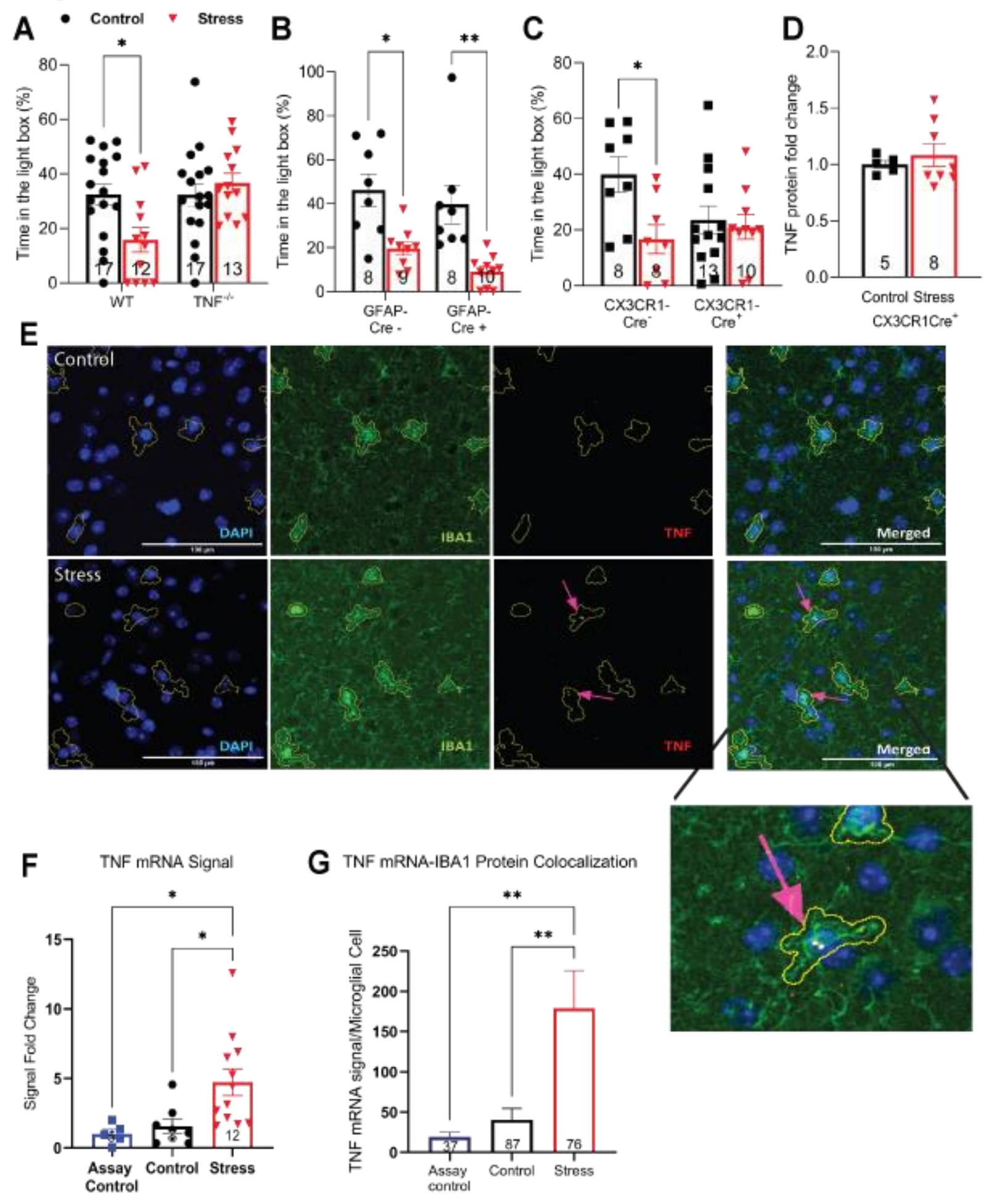


Figure 2: Microglial TNF signaling is important for the induction of stress-induced anxietylike behavior.

A. Mice that lack global TNF production do not show induction in anxiety-like behavior. (twoway ANOVA genotype $\mathrm{x}$ stress interaction $\mathrm{F}(1,55)=6.536, \mathrm{P}=0.0134$; Tukey's post hoc analysis of control versus stress within $\mathrm{WT} \mathrm{P}=0.0324, \mathrm{TNF}^{-/-} \mathrm{P}=0.8689$ ).

B. Stressed CX3CR1-Cre positive animals lack stress-induced increase in anxiety-like behavior compared to their unstressed counterparts. CX3CR1-Cre negative animals show a comparable phenotype to WT (24 h; two-way ANOVA main effect of stress $\mathrm{F}(1,35), \mathrm{P}=0.0227$; main effect of genotype $\mathrm{F}(1,35)=1.222, \mathrm{P}=0.2765$; interaction of stress $\mathrm{x}$ genotype $\mathrm{F}(1,35)=$ $3.679, \mathrm{p}=0.0633)$. Tukey's post hoc reveals that for Cre negative, control versus stress $\mathrm{P}=$ 0.0384 while for Cre positive, control versus stress $\mathrm{P}=0.9836$ ).

C. Stress induces anxiety-like behavior in GFAP-Cre positive animals compared to their unstressed GFAP-Cre positive counterparts, similar to the phenotype in WT animals (24 h; twoway ANOVA main effect of stress $\mathrm{F}(1,31)=25.53, \mathrm{p}<0.0001$; Tukey's post hoc analysis: Cre negative control versus stress $\mathrm{P}=0.0127$, Cre positive control versus stress $\mathrm{P}=0.0028$ ).

D. Microglial-TNF-lacking animals lack stress-induction of TNF in the vHPC compared to their controls (two-tailed student t-test, $\mathrm{P}=0.5355$ ).

E. Sample images demonstrating the results of RNAscope in situ hybridization combined with IBA1 immunohistochemistry staining in the vCA1-SR, using a bacterial probe and TNF mRNA probes in unstressed controls and stressed animals. The results are quantified in $\mathrm{F}$ and $\mathrm{G}$.

F. Stress induces TNF mRNA in the SR of the vHPC ( 4 h post-stress; one-way ANOVA, main effect $\mathrm{F}(2,22), \mathrm{P}=0.0096$; Tukey's post hoc analysis of control versus stress $\mathrm{P}=0.0288$, stress versus nonspecific signal $P=0.0271$, control versus nonspecific signal $P=0.9182$, Sample size $n$ (number of animals $\mathrm{N}$ ) for assay control $=5$ (3), for unstressed controls $=8$ (4), for stressed animals $=12(6))$.

G. Quantification of the overlap in in situ hybridization signal and microglial cells in all three conditions. (4 h post-stress; one-way ANOVA main effect $\mathrm{F}(2,197)=7.144, \mathrm{P}=0.001$; Tukey's post-hoc analysis of control versus stress $\mathrm{P}=0.0029$, control versus nonspecific signal $\mathrm{P}=$ 0.9108 , stress versus nonspecific signal $\mathrm{P}=0.0082$, number of detected microglia $\mathrm{n}$ ' (number of sections $\mathrm{n}$ - number of animals $\mathrm{N}$ ) for assay control $=37$ (3-2), for unstressed controls $=87$ (63 ), for stressed animals $=76(5-3))$.

${ }^{*} \mathrm{P}<0.05, * * \mathrm{P}<0.01,{ }^{* * *} \mathrm{P}<0.001$. Data are presented as mean $\pm \mathrm{SEM}$. TNF, tumor necrosis factor; vHPC, ventral hippocampus. Sample sizes are indicated on the figures. 
Figure 3
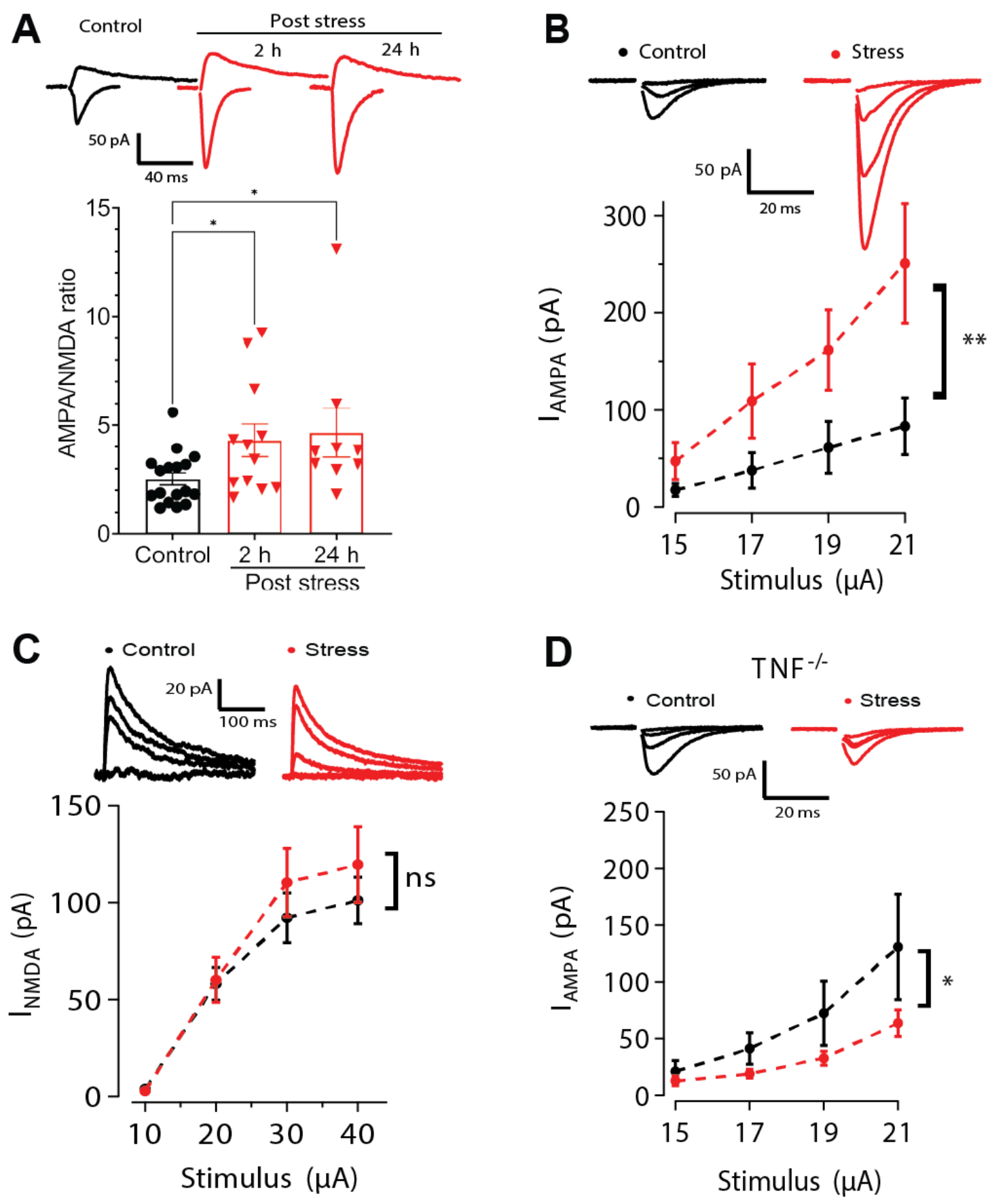
Figure 3. AMPAR-mediated currents at the Schaffer collateral synapses in vCA1 are potentiated in WT animals and not in $\mathrm{TNF}^{-/-}$mice.

A. Acute swim stress increases the AMPA/NMDA current ratio at Schaffer collateral synapses in the vCA1 at 2 and $24 \mathrm{~h}$ post-stress, as seen in sample traces and group data (Kruskal Wallis $\mathrm{H}(2)$ $=8.068, \mathrm{P}=0.0177$; Control: $\mathrm{n}=17, \mathrm{~N}=11 ; 2 \mathrm{~h}$ post-stress: $\mathrm{n}=13, \mathrm{~N}=8 ; 24$ h post-stress: $\mathrm{n}=$ $9, \mathrm{~N}=5)$.

B. Stress potentiates the AMPA receptor (AMPAR) input-output relationship in the ventral Schaffer collaterals $(24 \mathrm{~h}$ post-stress; two-way ANOVA of the main effect of stress $\mathrm{F}(1,40)=$ 11.439, $\mathrm{P}=0.0016$; control: $\mathrm{n}=5, \mathrm{~N}=4$, stress: $\mathrm{n}=7, \mathrm{~N}=3$ )

C. There is no significant stress-induced potentiation of the NMDA receptor (NMDAR) mediated input-output curve in the ventral Schaffer collaterals ( $24 \mathrm{~h}$ post-stress; two-way ANOVA of the main effect of stress $\mathrm{F}(1,52)=1.0999, \mathrm{P}=0.2991$; control: $\mathrm{n}=7, \mathrm{~N}=4$, stress: $\mathrm{n}=8, \mathrm{~N}=4)$.

D. TNF lacking animals $\left(\mathrm{TNF}^{-/-}\right)$do not exhibit potentiation in the AMPAR currents in the ventral hippocampus in response to stress-exposure ( $24 \mathrm{~h}$ post-stress; two-way ANOVA of the main effect of stress $F(1,44)=6.315, P=0.0157$; control: $n=6, N=3$, stress: $n=7, N=4)$.

$* \mathrm{P}<0.05, * * \mathrm{P}<0.01, * * * \mathrm{P}<0.001$. Data are presented as mean $\pm \mathrm{SEM}$. Sample sizes are indicated on the bar figure or in the caption. 
Figure 4

A

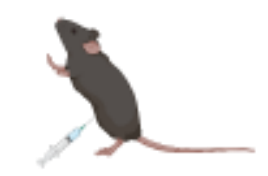

DN-TNF (IP) (Fig B-C)

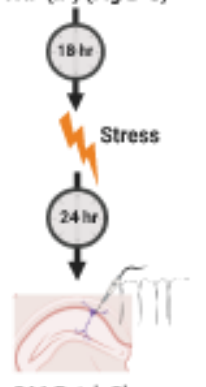

vCA1 Patch Clamp

D
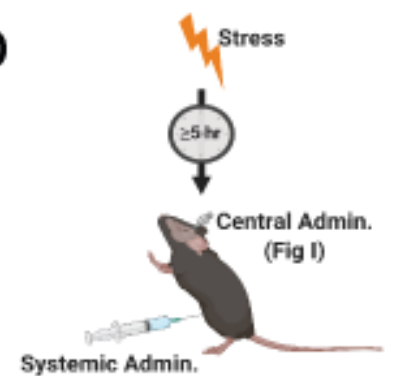

(Fig E-H)

$\int_{t}^{42 \pi x}$

(Fig E-F)

(Fig G-1)

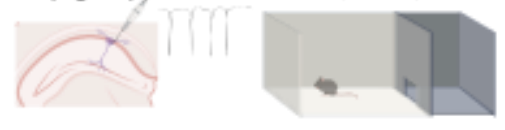

G Systemic Administration

- Control ₹ FST Stress

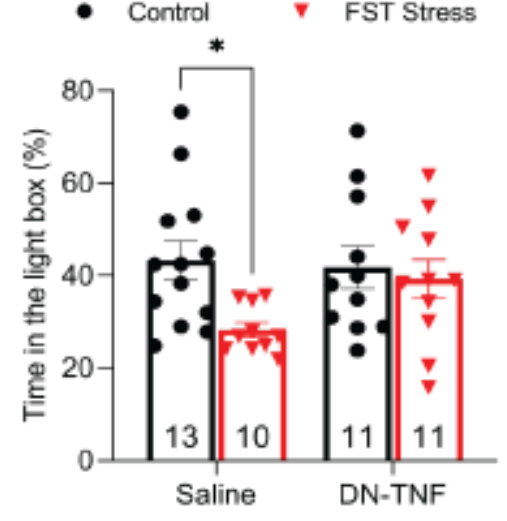

Saline

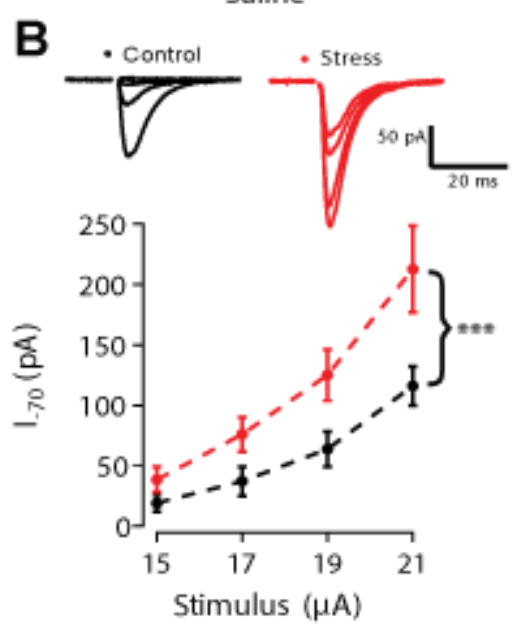

Saline
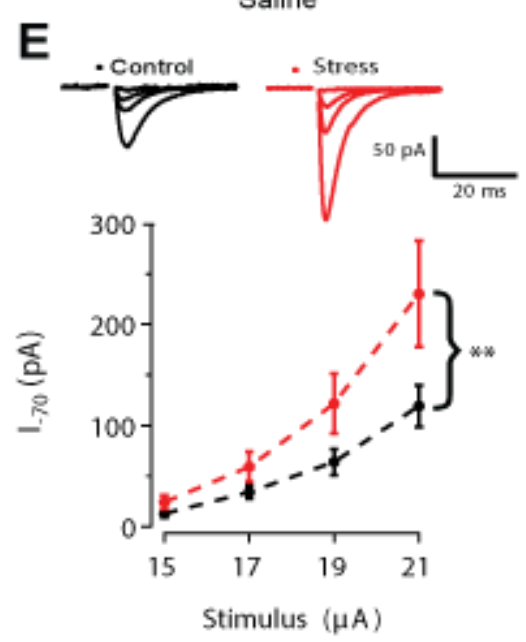

H

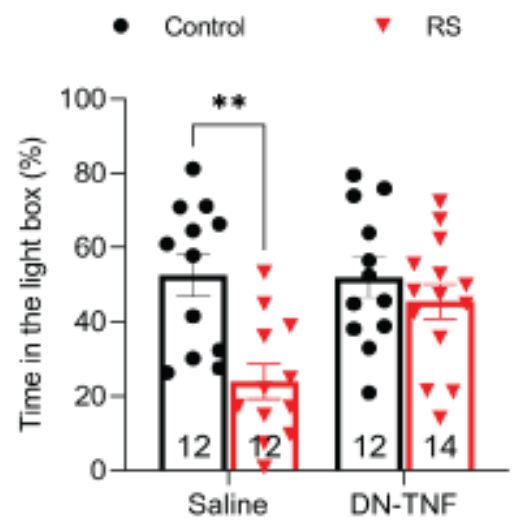

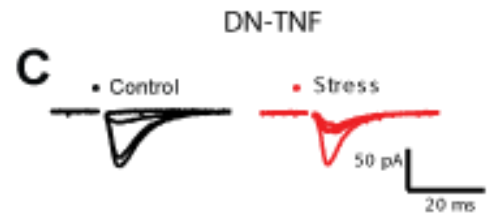
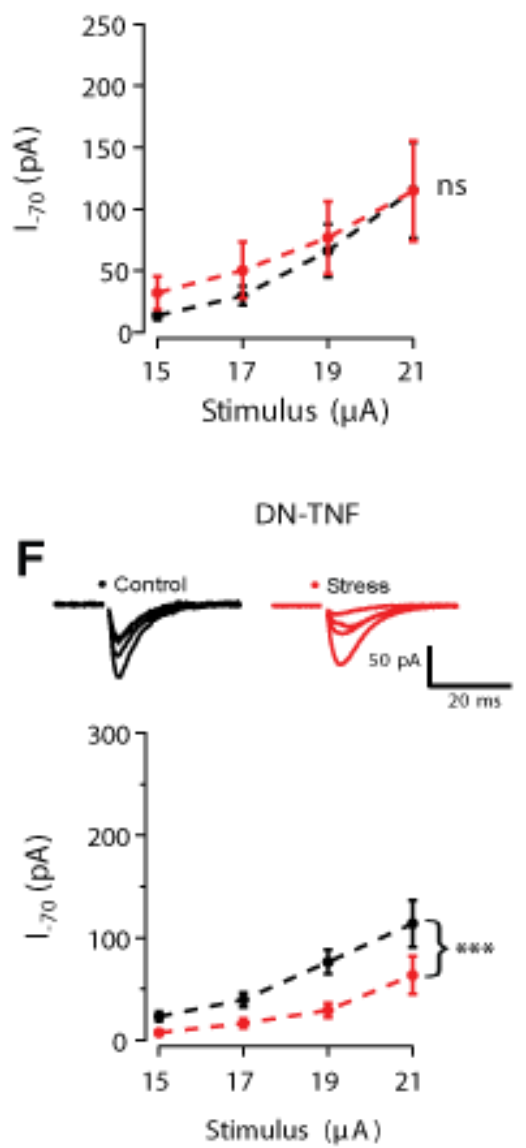

Systemic Administration l Central Administration 
Figure 4: TNF antagonism post-stress reverses stress-induced plasticity and behavior.

A. A schematic of the experiments performed in B and C.

B. Systemic (IP) administration of saline prior to stress does not interfere with stress-induced AMPAR current potentiation at VCA1-SC synapses (two-way ANOVA of the main effect of stress $F(1,58)=14.5093, P=0.0003$; control: $n=7, N=5$, stress: $n=10, N=6)$.

C. Blocking TNF signaling through systemic (IP) administration of dominant negative TNF (DNTNF; $20 \mathrm{mg} / \mathrm{kg}$ ) prior to stress blocks the observed potentiation (two-way ANOVA of the main effect of stress $F(1,44)=0.4727, P=0.4954$; control: $n=7, N=3$, stress: $n=6, N=4)$.

D. A schematic of the experiments performed in E-I.

E. Administering saline IP at $5 \mathrm{~h}$ post-stress does not block AMPAR mediated, vCA1-SC synaptic potentiation observed at $48 \mathrm{~h}$ post-stress (two-way ANOVA of the main effect of stress $\mathrm{F}(1,84)=6.5693, \mathrm{P}=0.0122$; control: $\mathrm{n}=11, \mathrm{~N}=7$, stress: $\mathrm{n}=12, \mathrm{~N}=8$ ).

F. Systemic (IP) administration of DN-TNF 5h after stress blocks the expression of stressinduced synaptic potentiation (two-way ANOVA of the main effect of stress $\mathrm{F}(1,64)=14.78, \mathrm{P}$ $=0.0003$; control: $\mathrm{n}=10, \mathrm{~N}=5$, stress: $\mathrm{n}=8, \mathrm{~N}=5$ ).

G. Blocking TNF signaling via administering DN-TNF (IP; $20 \mathrm{mg} / \mathrm{kg} ; 5 \mathrm{~h}$ post-stress) prevents anxiety-like behavior 48h post-swim stress (two-way ANOVA of the main effect of stress F (1, $41)=4.825, \mathrm{p}=0.0338$; main effect of drug treatment $\mathrm{F}(1,41)=1.428, \mathrm{p}=0.2390$; interaction of stress $\mathrm{x}$ drug treatment $\mathrm{F}(1,41)=2.470, \mathrm{p}=0.1237$; Tukey's post hoc analyses of control saline versus FST saline $\mathrm{p}=0.0494$, control DN-TNF versus FST DN-TNF $\mathrm{p}=0.9714)$.

H. TNF is similarly necessary for stress-induction of anxiety-like behavior following restraint stress (two-way ANOVA of the interaction of stress $x$ drug treatment $F(1,46)=4.692$, $p$ $=0.0355$; Tukey's post hoc analyses of control saline versus RS saline $p=0.0017$, control DNTNF versus RS DN-TNF $\mathrm{p}=0.7908$ ).

I. Blocking TNF in the vHPC through local administration of DN-TNF (IC; $4.8 \mathrm{mg} / \mathrm{kg}$; $5 \mathrm{~h}$ post$\mathrm{RS}$ ) prevents the development of anxiety-like behavior $48 \mathrm{~h}$ in response to stress (two-way ANOVA of the interaction of stress $\mathrm{x}$ drug treatment $\mathrm{F}(1,24)=20.58, \mathrm{p}=0.0001$; Tukey's post hoc analyses of control saline versus RS saline $\mathrm{p}=0.0078$, of control DN-TNF versus RS DNTNF $\mathrm{p}=0.0419)$.

$* \mathrm{P}<0.05, * * \mathrm{P}<0.01, * * * \mathrm{P}<0.001$. Data are presented as mean $\pm \mathrm{SEM}$. Sample sizes are indicated on the bar figure or in the caption. 


\section{Supplementary 1}
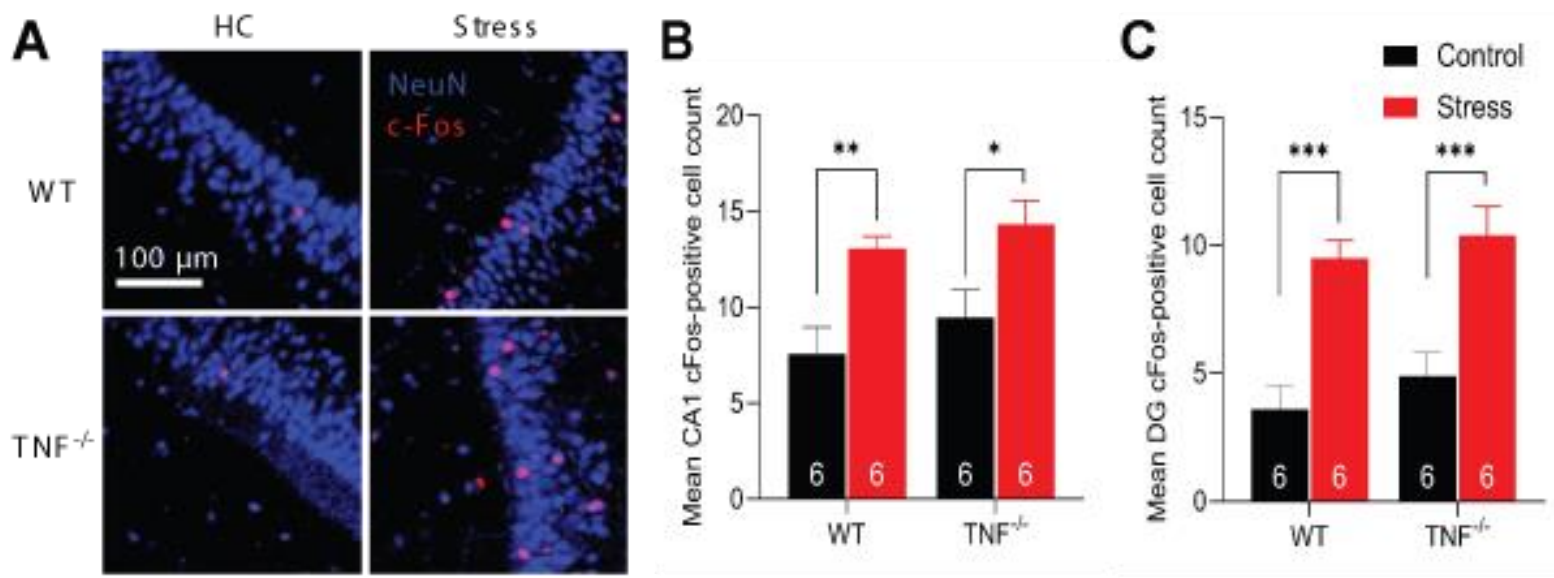

\section{Supplementary 2}
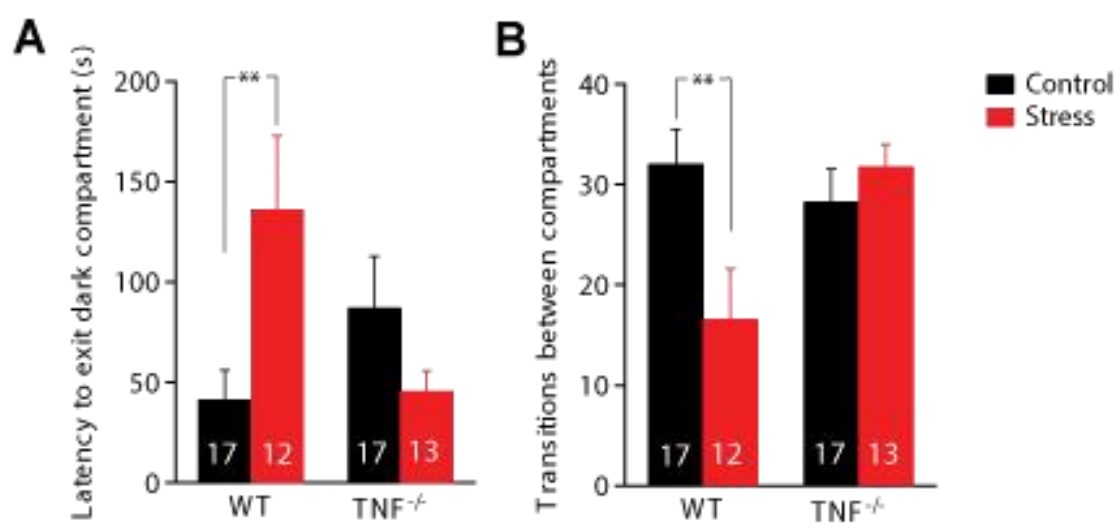

\section{Supplementary 3}

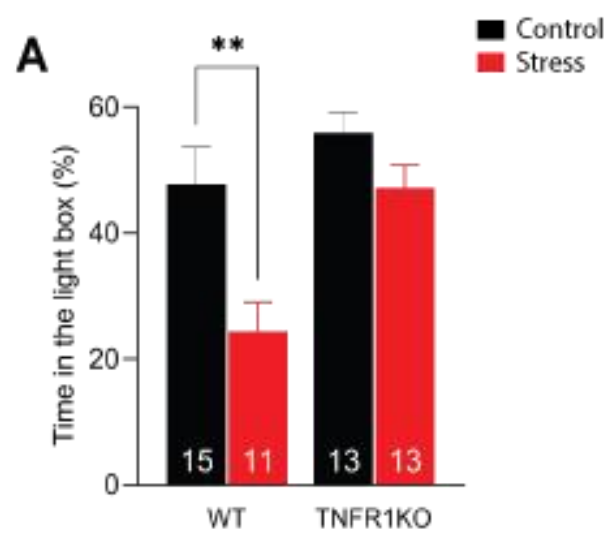


S1. A c-Fos labelling of the CA1 of the vHP in control and stressed animals. Labelling was significantly increased in the CA1 $(\mathbf{B})$ and dentate gyrus $(\mathbf{C})$ in both WT $(\mathrm{P}<0.001)$ and $\mathrm{TNF}^{-/-}$ $(\mathrm{P}<0.001)$ animals following stress. There were no statistically significant differences between genotypes under control conditions $(\mathrm{P}=0.34)$, nor following stress $(\mathrm{P}=0.51)$.

S2. A. Latency to first exit in the light-dark box is longer in stressed wild-type (WT) animals compared to TNF knockout $\left(\mathrm{TNF}^{--}\right.$) mice (two-way ANOVA genotype $\mathrm{x}$ stress interaction $\mathrm{F}$ (1, $49)=9.140, \mathrm{P}=0.0040$; Tukey's post hoc analysis of control versus stress within WT $\mathrm{p}=$ 0.0376, $\mathrm{TNF}^{-/-} \mathrm{p}=0.4996$; Tukey's post hoc $\mathrm{WT}$ versus $\mathrm{TNF}^{-/-}$within controls $\mathrm{p}=0.3646$ ).

B. Stress reduces the number of transitions WT animals make from the dark box to the light box, while it does not affect the same parameter in $\mathrm{TNF}^{-/-}$mice (two-way ANOVA genotype $\mathrm{x}$ stress interaction $\mathrm{F}(1,55)=6.992, \mathrm{P}=0.0107$; Tukey's post hoc analysis of control versus stress within WT $\left.\mathrm{p}=0.0195, \mathrm{TNF}^{-/-} \mathrm{p}=0.8990\right)$.

S3. No stress-induced anxiety-like behavior was observed in TNFR1KO animals $(24 \mathrm{~h}$ poststress; two-way ANOVA main effect of genotype $F(1,48)=10.97, p=0.0018$, main effect of stress $F(1,48)=11.73, p=0.0013$, genotype $x$ stress interaction $F(1,48)=2.434, p=0.1253$. Tukey's post hoc analysis: difference within WT $\mathrm{p}=0.0054$, difference within TNFR1KO $\mathrm{p}=$ 0.5509).

${ }^{*} \mathrm{P}<0.05, * * \mathrm{P}<0.01,{ }^{* * *} \mathrm{P}<0.001$. Data are presented as mean $\pm \mathrm{SEM}$. Sample sizes are indicated on the figures. 


\section{Supplementary 4}

A

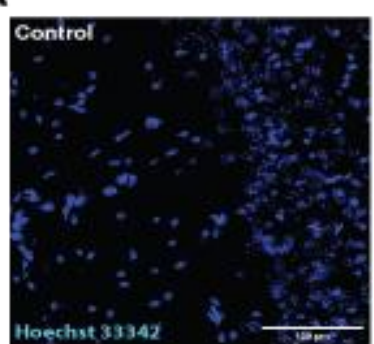

Stress
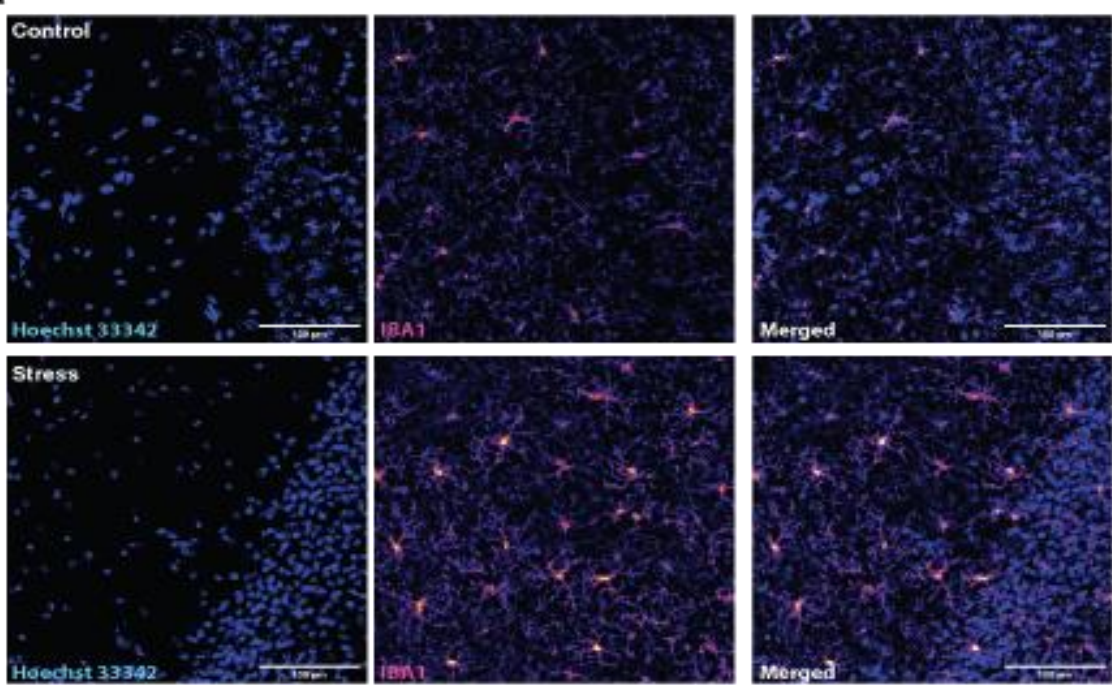

\section{Hull-Circle Fitting Sample}

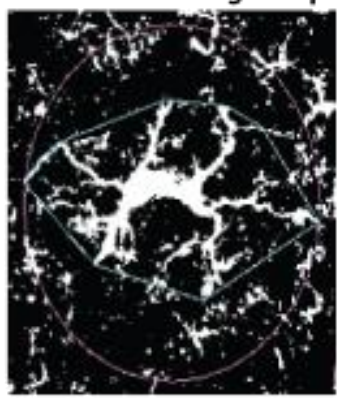

\section{E}

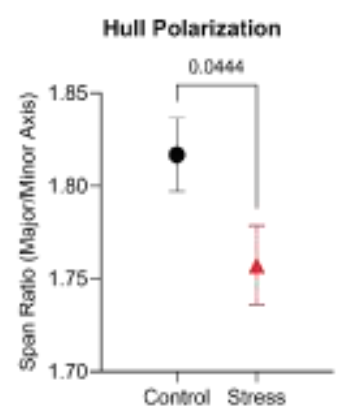

F

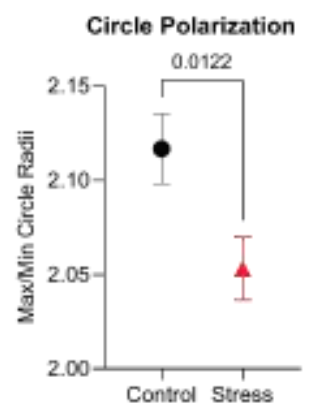

B

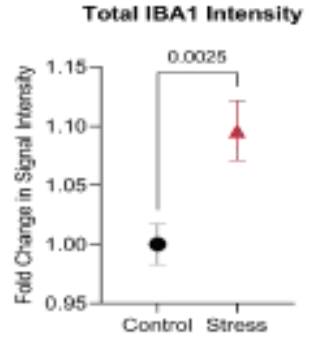

C Detected IBA1+ Cells

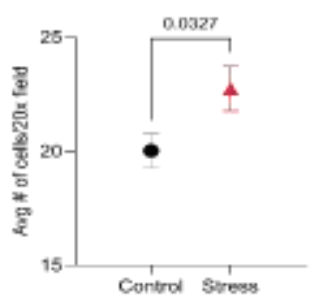

G

Circularity of the Hull

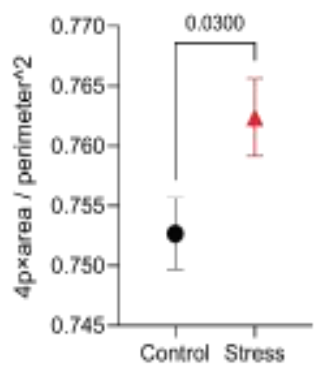


S4. A. Sample images demonstrating microglial activation as proxied by IBA1 signalling and cell density.

S4. B. Quantification of total IBA1 signa in the vHPC-CA1 region of unstressed controls and acutely stressed animals ( $4 \mathrm{~h}$ post-stress, student t-test, $\mathrm{p}=0.0025$, sample size $\mathrm{n}$ (number of animals $\mathrm{N}$ ) for control $=43(4)$, for stress $=45(4))$.

S4. C. Quantification of microglia in control versus stress ( $4 \mathrm{~h}$ post-stress, student $\mathrm{t}$-test, $\mathrm{p}=$ 0.0327).

S4. D. \& E. An illustration of the pipeline for fitting microglia in a hull (inner green shape) and a circle (outer purple shape) for quantitative analysis of microglial morphology. The convex hull of a cell is the smallest convex set that encompass the cells. A convex set is a polygon where the line between any two points lies completely within the polygon. Microglia was delineated semiautomatically and the hull and circle shapes were fitted automatically using Frac-Lac package in ImageJ.(Karperien, 1999-2013.)

S4. F-H. Quantification of three parameters of the circularity of microglia, namely the polarization of the fitted hull $(\mathrm{p}=0.0444)$, the polarization of the fitted circle $(\mathrm{p}=0.0122)$, and the circularity of the hull ( $\mathrm{p}=0.03$, all parameters were analyzed using a student t-test, $\mathrm{n}(\mathrm{N})$ for control $=43$ (4), for stress $=45$ (4), see the y axes for the equations used to measure each variable).

vHPC: ventral hippocampus, n: sample size, N: number of animals 


\section{Supplementary 5}

\section{A}

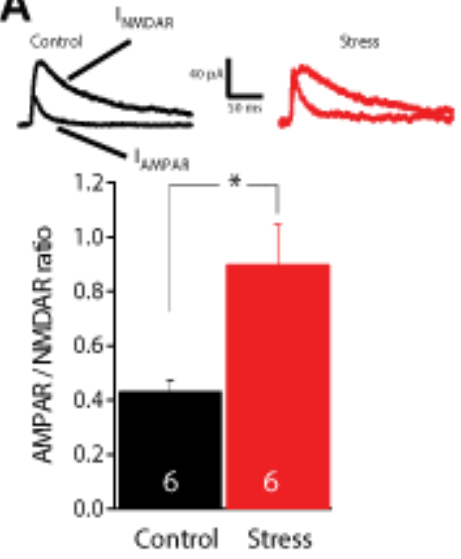

D

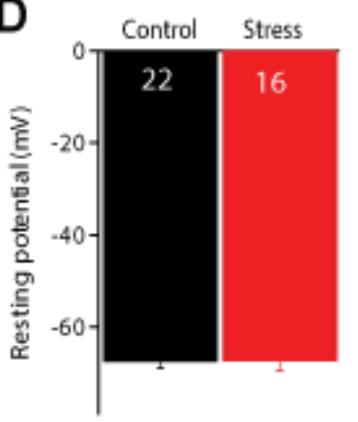

B
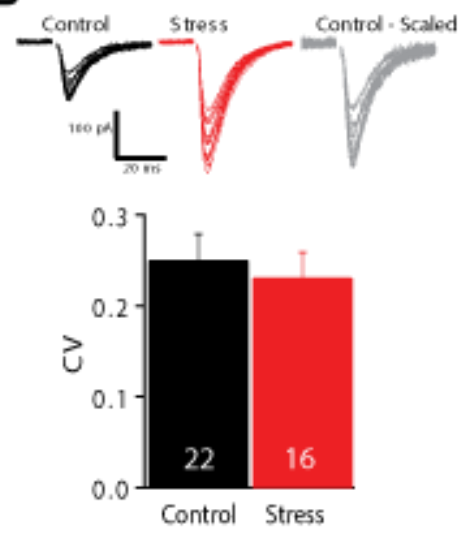

E

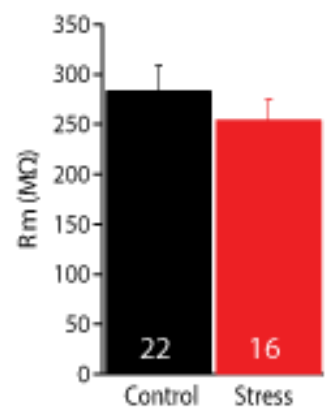

C
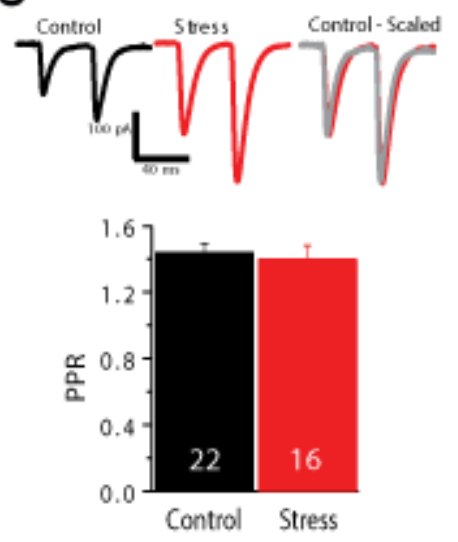

F

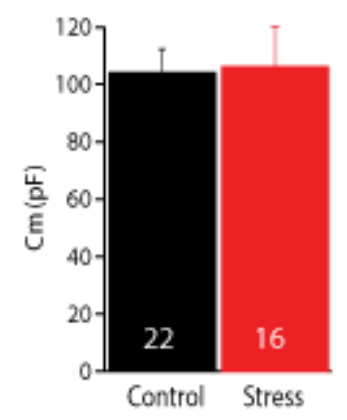


S5. A. Cells in the baseline and $24 \mathrm{~h}$ post stress groups were perfused with D-AP5 subsequent to depolarization to $+40 \mathrm{mV}$ to isolate the AMPAR current. Example traces illustrate the isolated AMPAR current (black trace) which was subtracted from the compound current (not illustrated) to produce the resultant (isolated) NMDAR current (red trace). The peaks of the AMPAR current and NMDAR current were used in calculation of the AMPAR / NMDAR ratio data. Two-tailed t-test comparison of baseline $(n=6, N=4)$ against the 24 h post stress is shown in figure S3.A. B. There were no significant changes in measures of pre-synaptic release probability, coefficient of variability $(\mathrm{CV} ; \mathrm{P}=0.64)$ and $\mathbf{C}$. paired pulse ratio (PPR; $\mathrm{P}=0.66)$ (stress: $n=16, \mathrm{~N}=8$; control: $n=22, N=15$ ) measured 24 h post stress. Grey traces illustrate the example traces shown for control condition, scaled to match mean current amplitude for stress condition for comparison. The left panels illustrate individual synaptic response sweeps overlaid to highlight sweep-to-sweep variability. D. There were no significant differences between stress and control groups in resting membrane potential $(\mathrm{P}=0.94)$, E. membrane resistance $(\mathrm{Rm} ; \mathrm{P}=0.40)$, nor in F. cell capacitance $(\mathrm{Cm} ; \mathrm{P}=0.90)$. For all:, stress $n=16 ; N=8$; control: $n=22, N=15$.

$* \mathrm{P}<0.05, * * \mathrm{P}<0.01,{ }^{*} * \mathrm{P}<0.001$. Data are presented as mean \pm SEM. Sample sizes are indicated on the figures. 


\section{Supplementary 6}

A

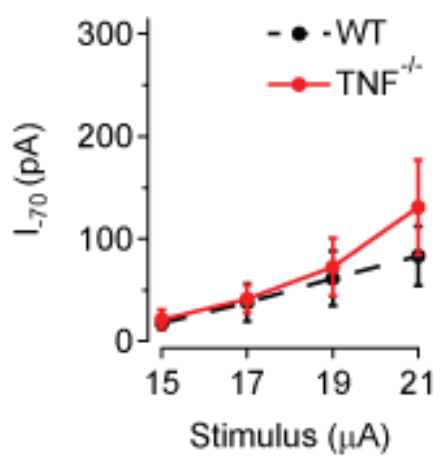

B

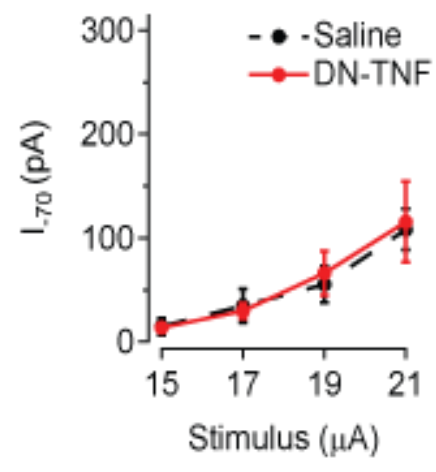

\section{Supplementary 7}

A

WT

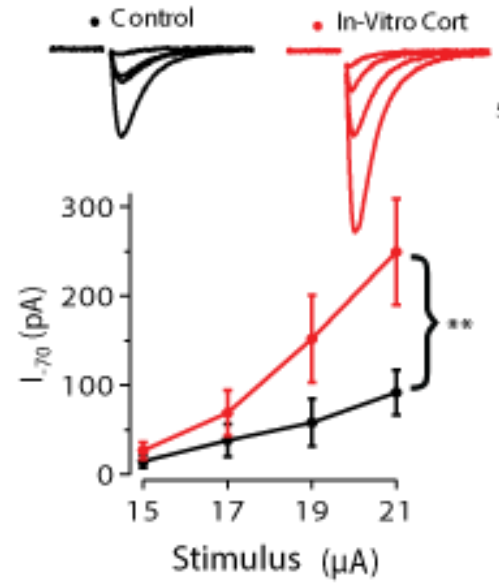

B $\quad \mathrm{TNF}^{-\mathrm{t}}$

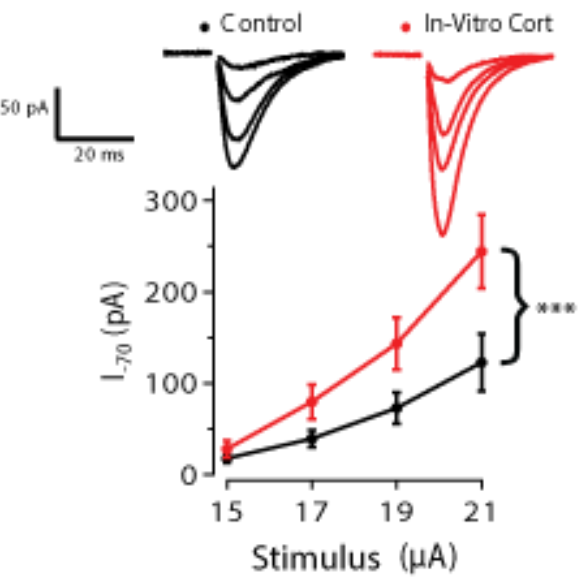


S6. A. There was no significant difference in basal AMPAR current in ventral hippocampus SC to CA1 synapses between WT animals and $\mathrm{TNF}^{-/-}\left(P=0.16 ; \mathrm{WT}: \mathrm{n}=7, \mathrm{~N}=5 ; T N F^{-/}: \mathrm{n}=6, \mathrm{~N}=3\right)$. B. Administration of DN-TNF did not alter basal AMPAR current relative to saline-injected controls $(P=0.58$; Sal: $\mathrm{n}=18, \mathrm{~N}=12$; DN-TNF: $\mathrm{n}=17, \mathrm{~N}=8)$.

S7. A. Ex-vivo application of CORT induces synaptic potentiation of the vHPC-CA1 in both WT (Two-way ANOVA main effect of treatment $\mathrm{F}(1,34)=8.3866, \mathrm{P}=0.0066$; control: $\mathrm{n}=4, \mathrm{~N}=4$; CORT: $\mathrm{n}=7, \mathrm{~N}=4)$ and $\mathbf{B} . \mathrm{TNF}^{-/}($Two-way ANOVA main effect of treatment $\mathrm{F}(1,48)=$ 13.8841, $\mathrm{P}=0.0005$; control: $\mathrm{n}=7, \mathrm{~N}=5$; CORT: $\mathrm{n}=7, \mathrm{~N}=5$ ).

$* \mathrm{P}<0.05, * * \mathrm{P}<0.01, * * * \mathrm{P}<0.001$. Data are presented as mean $\pm \mathrm{SEM}$. Sample sizes are indicated on the captions. 


\section{Supplementary 8}
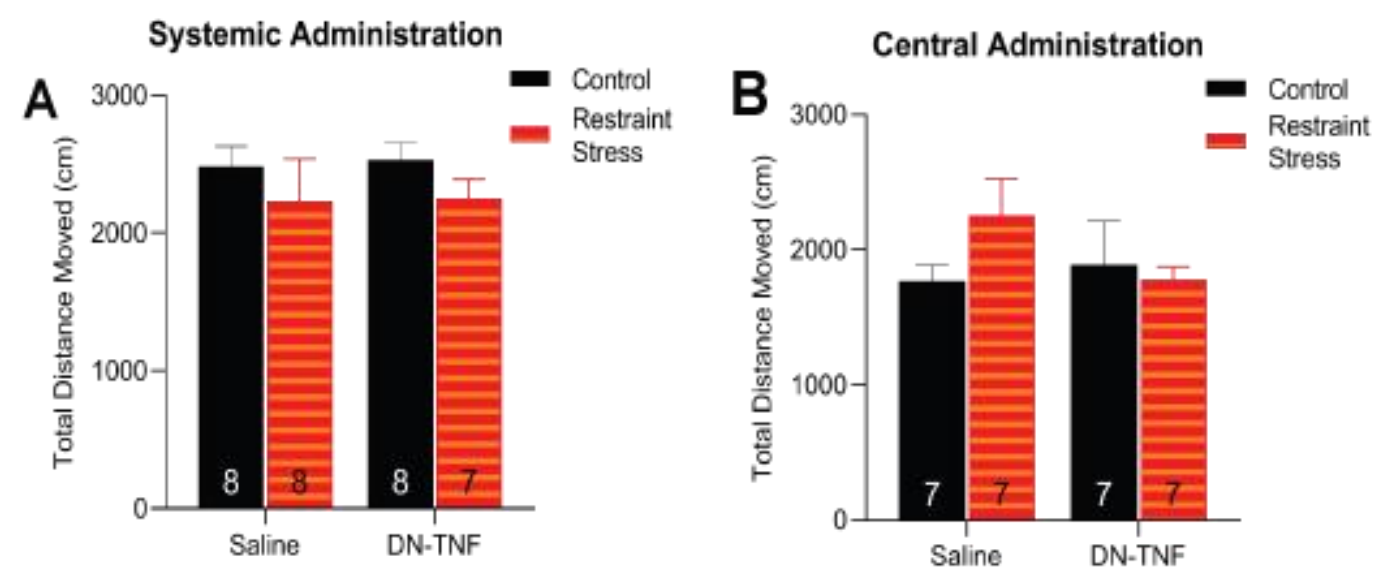

\section{Supplementary 9}
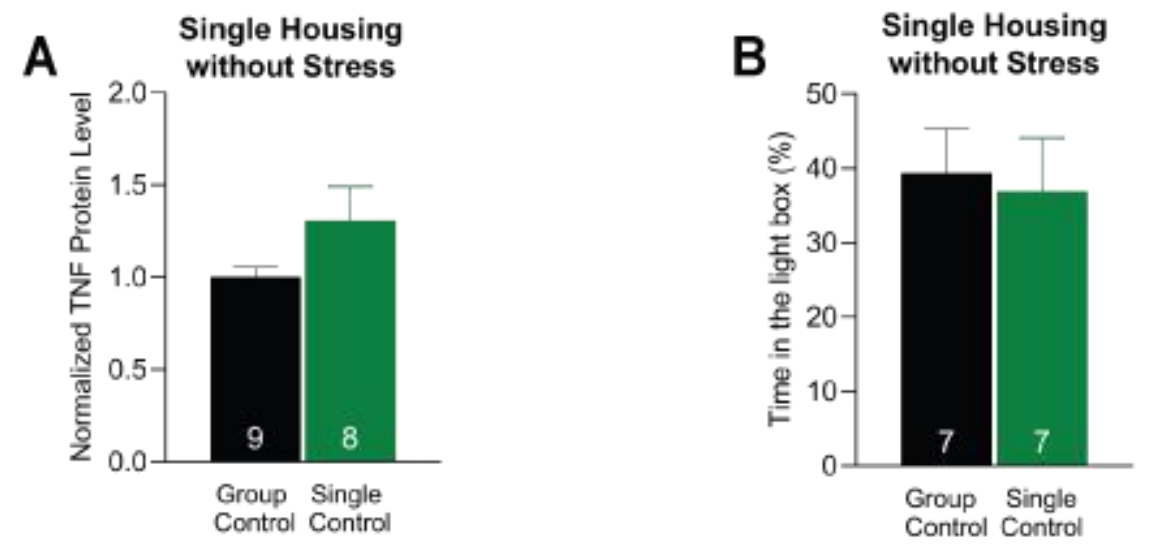

\section{Supplementary 10}

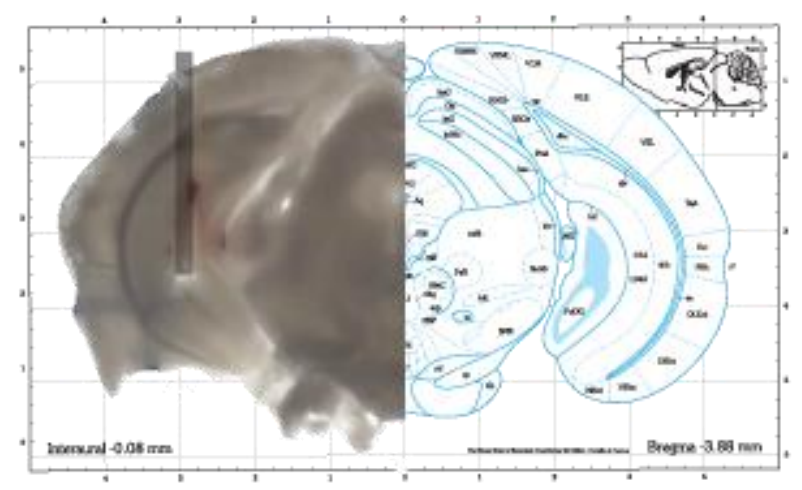

Cannula Placement 
S8.A. The observed phenotype is not driven by the effects of the drug treatment on locomotion, as there was no difference in the distance travelled across the different groups (two-way ANOVA of drug treatment $\mathrm{F}(1,27)=0.02533, \mathrm{P}=0.8747$; Tukey's post hoc analyses of control saline versus $R S$ saline $P=0.7978$, control DN-TNF versus RS DN-TNF $P=0.7591$ ).

B. There is no difference in distance travelled under low anxiogenic conditions between the four groups, therefore, the observed behavioral effect of drug treatment is not mediated by differences in locomotive behavior (two-way ANOVA of the main effect of drug $\mathrm{F}(1,24)=0.6220$, $p$ $=0.4380$; Tukey's post hoc analyses of control saline versus $\mathrm{RS}$ saline $\mathrm{P}=0.4359$, control DNTNF versus RS DN-TNF P $=0.9860$ ).

S9.A. There is no induction of vHPC levels of TNF in single-housed animals without stress (two-tailed student t-test, $\mathrm{P}=0.1124$ ). B. Single housing adult WT males over for $24 \mathrm{~h}$ does not induce anxiety-like behavior (two-tailed student t-test, $\mathrm{P}=0.7999$ ).

S10. A schematic and an image of the placement of the central cannula in the vHPC-CA1. The schematic portion of the figure was obtained from the Mouse Brain Atlas with permission.

${ }^{*} \mathrm{P}<0.05, * * \mathrm{P}<0.01, * * * \mathrm{P}<0.001$. Data are presented as mean $\pm \mathrm{SEM}$. RS, restraint stress. DN-TNF, dominant negative tumor necrosis factor; vHPC, ventral hippocampus. Sample sizes are indicated on the figures. 